\title{
Myxobacteria, Polarity, and Multicellular Morphogenesis
}

\author{
Dale Kaiser ${ }^{1}$, Mark Robinson ${ }^{2}$, and Lee Kroos ${ }^{2}$ \\ ${ }^{1}$ Departments of Biochemistry and of Developmental Biology, Stanford University School of Medicine, \\ Stanford, California 94305 \\ ${ }^{2}$ Department of Biochemistry and Molecular Biology, Michigan State University, East Lansing, Michigan 48824 \\ Correspondence: adkaiser@stanford.edu
}

Myxobacteria are renowned for the ability to sporulate within fruiting bodies whose shapes are species-specific. The capacity to build those multicellular structures arises from the ability of $M$. xanthus to organize high cell-density swarms, in which the cells tend to be aligned with each other while constantly in motion. The intrinsic polarity of rod-shaped cells lays the foundation, and each cell uses two polar engines for gliding on surfaces. It sprouts retractile type IV pili from the leading cell pole and secretes capsular polysaccharide through nozzles from the trailing pole. Regularly periodic reversal of the gliding direction was found to be required for swarming. Those reversals are generated by a G-protein switch which is driven by a sharply tuned oscillator. Starvation induces fruiting body development, and systematic reductions in the reversal frequency are necessary for the cells to aggregate rather than continue to swarm. Developmental gene expression is regulated by a network that is connected to the suppression of reversals.

\section{THE ORIGIN OF MYXOBACTERIA}

$R^{2}$ oughly 50 species of myxobacteria are recognized in the soil and on the bark of trees, around the earth (Reichenbach 1984). As chemo-organotrophs that feed on particulate organic matter, many myxobacteria are proteolytic — a habit associated with predation. Myxococcus xanthus hydrolyzes proteins and nucleic acids, to obtain essential amino acids and phosphate. M. xanthus growth is not enhanced by mono- or disaccharides (Dworkin 1962). Initially surprising, Dworkin's observation reflects their use of the Embden-Myerhof pathway for gluconeogenesis starting from amino acids during growth, rather than using the pathway for glycolysis. Amino acids are also converted to acetyl-CoA, which enters the TCA cycle to provide energy. This metabolic sketch of $M$. xanthus finds support in a recent genomic analysis that also shows their capacity to scavenge purines and pyrimidines (Curtis and Shimkets 2008).

Sorangium cellulosum exemplifies a myxobacterial cellulolytic feeding habit. Digestion of cellulose fibers (filter paper) yields glucose, which enters glycolysis and the TCA cycle to supply its carbon and energy (Schneiker et al. 2007). All myxobacteria are copious secretors of polysaccharide slime (the reason for the

Editors: Lucy Shapiro and Richard Losick

Additional Perspectives on Cell Biology of Bacteria available at www.cshperspectives.org

Copyright (C) 2010 Cold Spring Harbor Laboratory Press; all rights reserved; doi: 10.1101/cshperspect.a000380

Cite this article as Cold Spring Harb Perspect Biol 2010;2:a000380 
prefix "myxo"). Glucose from cellulose would, via the pentose phosphate pathway, give rise to many other hexoses and pentoses that are used to synthesize polysaccharides, including their capsule of slime and their lipopolysaccharide. Nitrate, ammonia, or amino acids can serve as nitrogen sources for S. cellulosum.

Representing a third habit, Stigmatella aurantiaca can efficiently digest chitin (Reichenbach 1993). Unlike the proteolytic M. xanthus, growth of $S$. aurantiaca is enhanced by the addition of glucose (Reichenbach and Dworkin 1969), indicating that glycolysis feeds pyruvate to its TCA cycle. Other particulate polysaccharides, such as agar, starch, pectin, and keratin can serve as carbon and energy sources for other myxobacteria, whose metabolic sketches have yet to be made. Overall, the ability to glycolyze sugars is correlated with a habit of feeding on polysaccharides, whereas gluconeogenesis is perfectly correlated with feeding on proteins.

Roland Thaxter, a cryptogamic botanist, was the first to describe myxobacterial cells. He reported (Thaxter 1892) that Chondromyces crocatus was a bacterium, which was shocking at the time because $C$. crocatus had for more than 20 years been considered an imperfect fungus: Its slime and morphologically complex fruiting bodies recall the slime molds (Fig. 1). Thaxter had discovered the unicellular vegetative stage of $C$. crocatus. The cells he found divided by binary fission; clearly the growing cells were not a fungal mycelium. Thaxter also described their multicellular behavior: locomotion, swarming, aggregation, and the process of fruiting body formation of $C$. crocatus and its relatives. Thaxter clearly saw the process of fructification as a "course of development" because it was "a definitely recurring aggregation of individuals capable of concerted action toward a definite end." The remarkable morphogenetic capacity of M. xanthus is outlined in Figure 2.

Hans Reichenbach recorded myxobacterial swarming and fruiting body development in a most informative series of time-lapse movies, documenting the complex yet orderly behavior of cells in several different species of myxobacteria (Reichenbach 1966; Reichenbach 1968; Reichenbach 1974). The movies show that swarming, which enables their rapid spreading over surfaces such as agar, is systematically modified by starvation to enable their sporulation within species-specific fruiting bodies.

The evolutionary origin of the myxobacteria, which are monophyletic, is found within the delta subgroup of proteobacteria, according to the sequence of their 16S ribosomal RNA (Sproer et al. 1999). Among the proteobacteria, only the myxobacteria have the capacity to develop multicellular fruiting bodies whose form is species specific. M. xanthus shares the ability to lyse and digest other bacteria with another $\delta$-proteobacterium, Bdellovibrio bacteriovorus (Evans et al. 2008). Indeed, predatory feeding may have evolved within the $\delta$-proteobacteria. Myxobacteria are abundant in cultivated top-soils around the earth because a wide variety of Gram- and Gram+ bacteria
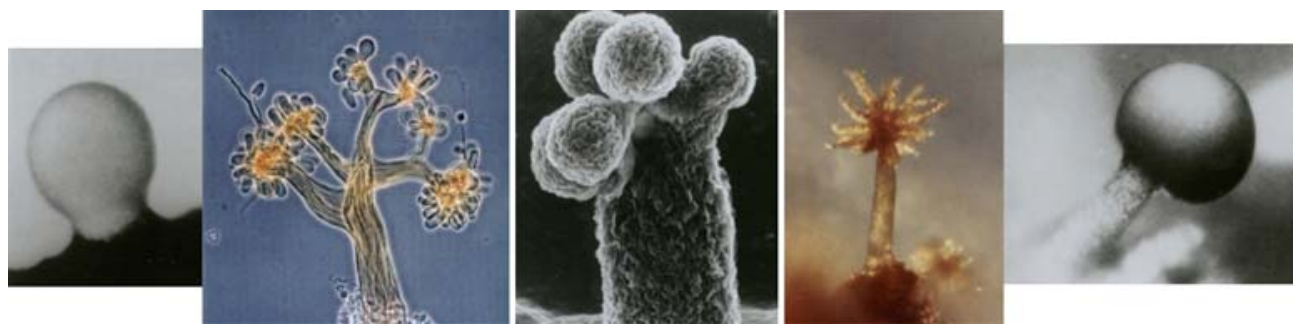

Figure 1. Fruiting bodies of five different species of myxobacteria are shown, illustrating differences in morphology. From left to right: Myxococcus xanthus, Chondromyces crocatus, Stigmatella aurantiaca, Chondromyces apiculatus, Myxococcus stipitatus. (Reprinted, with permission, from Kaiser 2008b [Annual Reviews].) 


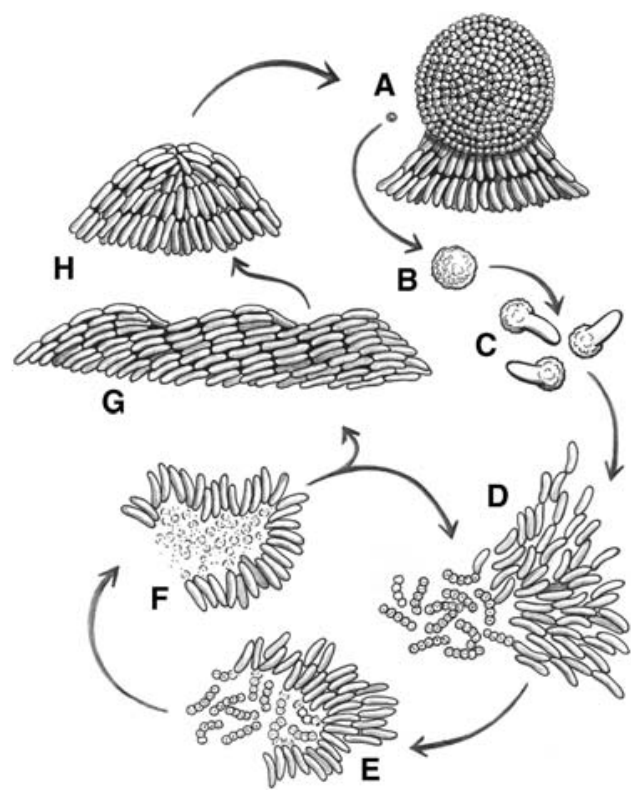

Figure 2. The lifecycle of Myxococcus xanthus. A group of swarming and interacting cells can have either of two fates depending on the swarm's environment. A Myxococcus fruiting body $(A)$ is a spherical structure of approximately $1 \times 10^{5}$ cells that contains stressresistant spores. The fruiting body is small $(1 / 10$ $\mathrm{mm})$, sticky, and its spores are tightly packed. When a fruiting body receives nutrients, the individual spores germinate and thousands of $M$. xanthus cells emerge together as an "instant" swarm $(B-D)$. When prey or other nutrient is available, the swarm becomes a predatory collective that moves and feeds cooperatively, pooling extracellular enzymes to lyse and consume prey bacteria $(E-F)$. Multicellular fruiting body development is advantageous given the collective hunting behavior of swarms. Nutrient-poor conditions elicit a unified starvation stress-response that leads to the formation of fruiting bodies. Other multicellular behaviors include wave formation $(G)$, streaming into aggregates $(H)$, and mound building (I). (Adapted from Goldman et al. 2006.)

are found in association with plants. For predation, $M$. xanthus, is seen to surround a prey colony, as diagrammed in steps $\mathrm{D}-\mathrm{F}$ of Figure 2, to make direct contact with the prey cell (Berleman et al. 2006), and to lyse the prey envelope. Then, it is thought to extract the cytoplasmic proteins of the prey, digest them to peptides and amino acids before consuming them for carbon, nitrogen and energy.
Apart from the Myxobacteria, the $\delta$-proteobacterial genomes range from 3.66 to $5.01 \mathrm{Mb}$. Because the M. xanthus genome is $9.14 \mathrm{Mb}$, there has been a genome enlargement of $4-5$ $\mathrm{Mb}$ from its inferred $\delta$ proteobacterial ancestor. Genome expansion specific to the myxobacterial lineage is strongly suggested by the almost identical genome sizes of S. aurantica $(9.5 \mathrm{Mb})$, Stigmatella erecta $(9.8 \mathrm{Mb})$, and $M$. xanthus $(9.14 \mathrm{Mb})$. More than 1500 gene duplications, representing $15 \%$ of the genome, have been identified in M. xanthus that are lineage-specific (Goldman et al. 2006). Genes were not duplicated at random. Instead, genes for cell-cell signaling, small molecule sensing, and integrative control of transcription were amplified selectively (Goldman et al. 2006). Evidently additional expansion within the Myxobacterial lineage led to Sorangium cellulosum, whose 13 Mbp genome (Schneiker 2007) encodes the largest number of serine/threonine protein kinases of any organism (Pérez et al. 2008).

Electron microscopy reveals that $M$. xanthus has a typical Gram-negative cell structure, which averages 7 microns in length and 0.5 microns in width, and that the peptidoglycan (murein) forms a rod-shaped sacculus. Nevertheless, their muropeptide profile is unusual, and the glycan strands are $1 / 3$ to $1 / 2$ the length of those in Escherichia coli (Bui et al. 2009). These compositional differences are correlated with the great flexibility of $M$. xanthus cells (Wolgemuth 2005). Flexibility is important for their gliding motility on surfaces that may be curved (Kaiser 2007). In addition the cells are polarized: each has a head and a tail. The ecological success of the myxobacterial lifestyle is witnessed by the millions of myxobacterial cells found per gram of cultivated soil (Reichenbach 1984).

\section{LOCOMOTION}

\section{S Motility}

Several pili extend forward from the leading end of each $M$. xanthus cell. Among the type IV pilus proteins common to M. xanthus, P. aeruginosa, N. gonorrhoeae, N. meningitigis, and Synecchocystis 
PCC6803, the most highly conserved include PilA, PilB, PilC, PilD, PilM, PilN, PilO, PilP, PilQ, and PilT (Table 1). The conserved pil genes are clustered together with their regulators in M. xanthus, facilitating genetic studies. Protein structure, function and intracellular location tend to be conserved, which has made it possible to unravel the molecular function of many of these proteins; see reviews (Mattick 2002; Nudleman and Kaiser 2004; Pelicic 2008).

Type IV pilins, which are encoded by the pilA gene, conserve only their amino terminal region of about 60 amino acids. Synthesized as a prepilin, PilA is processed by the PilD peptidase. Conservation of the PilA amino terminal sequence is thought to reflect the sequence requirements of PilD around the peptidase cleavage site (Strom et al. 1993), and the need of the amino terminal region to form an $\alpha$-helix that is capable of regularly staggered coiled-coiling with copies of itself. A structure was inferred from a $2.6 \AA$ resolution X-ray crystal structure of $N$. gonorrhoeae pilin dimers, a mapping of surface-exposed peptides, and cryo-electron microscopy (Craig et al. 2006).

Because individual pili are 3-10 $\mu \mathrm{m}$ long, whereas the rise per monomer is of the order of $1 \mathrm{~nm}$, a single pilus fiber includes many thousands of copies of the processed pilin (Hansen and Forest 2006). The $\beta$-strands of one pilin monomer in the helical filament interact with the $\beta$-strands of the next monomer, lending tensile strength to the fiber. The flexibility of the $\alpha$-helices in the fiber core that are held together by hydrophobic forces allows the fiber to bend, twist, and to bundle with other pilus fibers. Despite a diameter of only $6 \mathrm{~nm}$, the fiber can withstand tension stresses in excess of $100 \mathrm{pN}$ (Maier et al. 2002). Absence of a channel in the center of the pilus fiber implies that it is polymerized from its base in the inner membrane, where PilB and PilT are located to

Table 1. S motility genes

\begin{tabular}{|c|c|c|c|c|}
\hline Protein $^{a}$ & Function & Cellular localization & Clustered $^{\mathrm{b}}$ & $\begin{array}{c}\text { Conserved in } \\
\text { multiple species }{ }^{c}\end{array}$ \\
\hline PilA & $\begin{array}{l}\text { Pilin, monomer unit of the } \\
\text { pilus filament }\end{array}$ & $\begin{array}{l}\text { Assembled into the pilus fiber } \\
\text { Stored in the Inner Membrane }\end{array}$ & + & + \\
\hline PilB & Pilus extension & Inner membrane & + & + \\
\hline PilT & Pilus retraction & Inner membrane & + & + \\
\hline PilC & Unknown & Inner membrane & + & + \\
\hline PilD & PilA leader peptidase & Inner membrane & + & + \\
\hline PilG & ABC Transporter & Periplasm & + & \\
\hline PilH & ABC Transporter & Periplasm & + & \\
\hline Pill & ABC Transporter & Periplasm & + & \\
\hline PilM & ATPase & Inner membrane & + & + \\
\hline PilN & Unknown & Periplasm & + & + \\
\hline PilO & Unknown & Periplasm & + & + \\
\hline PilP & Unknown & Anchored in outer membrane & + & + \\
\hline PilQ & Secretin & Outer membrane & + & + \\
\hline PilR & $\begin{array}{l}\text { Regulates transcription } \\
\text { of pilA }\end{array}$ & & + & - \\
\hline Pils & $\begin{array}{l}\text { Two-component sensor } \\
\text { for pilR }\end{array}$ & & + & - \\
\hline PilR1 & Transcriptional regulator & & + & - \\
\hline PilS1 & $\begin{array}{l}\text { Two-component sensor } \\
\text { for pilR1 }\end{array}$ & & + & - \\
\hline Tgl & Secretin assembly factor & Outer membrane & - & - \\
\hline
\end{tabular}


Myxobacteria, Polarity, and Multicellular Morphogenesis

catalyze extension and retraction, respectively (Table 1).

M. xanthus cells, separated by more than a pilus length (several micrometer) are rarely, if ever observed to move (Kaiser and Crosby 1983). It is as if pili retract with great force only if their tips have firmly attached to fibrils on a group of cells ahead of them (Kaiser 1979; Merz et al. 2000; Semmler et al. 1999). $\mathrm{Li}$ et al. argue that binding is less strict ( $\mathrm{Li}$ et al. 2003). Fibrils, consisting of almost equal amounts of protein and polysaccharide that contains galactose, glucosamine, glucose, rhamnose, and xylose (Behmlander and Dworkin 1994; Dworkin 1999), make up a linked meshwork of amorphous strands, often $30 \mathrm{~nm}$ in diameter that bundle neighboring cells close together. Bundling is visible microscopically (Kearns and Shimkets 2001). Fibril-deficient mutant cells can accept fibrils from an extracellular polysaccharide fraction of normal cells ( $\mathrm{Lu}$ et al. 2005).

Certain M. xanthus mutants, which lack S motility (called $\mathrm{S}^{-}$mutants), retain pilus fibers. Examples include the pilT mutants, the dif or $d s p$ (dispersed growth) mutants, and certain lipopolysaccharide-defective mutants. Although pilTmutants grow in clumps, because their pili attach to fibrils, the $d s p$ and the dif mutants grow dispersed in liquid culture. These genes are likely to encode regulators of fibril production because the mutants are fibrildeficient (Lu et al. 2005). It appears that both fibrils (and perhaps $\mathrm{O}$-antigen) influence the number of pili that cells assemble. Pili are thought to work as follows: The relatively stiff pilus extends ahead of an $M$. xanthus cell, it adheres to fibrils on cells located near the pilus tip, retracts, and pulls the piliated cell forward toward the cells ahead. Once an attachment has been made the connection with fibrils on the target cell can withstand $100 \mathrm{pN}$ of pulling force. The cell group to which the pilus has attached moves but slightly because the group, having more cells, adheres with greater strength to the substrate than the piliated cell which has contributed ATP for retraction. Finally, the group of cells bundled by fibrils enlarges by one cell.

\section{Assembly of Type IV Pili}

The type IV pilus engine includes more than 15 different proteins (Table 1). Some protein constituents are found in the cytoplasmic membrane, others reach across the periplasm, and may be anchored to the peptidoglycan. Still others pass through the outer membrane into the extracellular space, as diagrammed in Figure 3. Many thousands of pilA monomers are joined to form the helical pilus fiber. That fiber passes through the doughnut-shaped assembled PilQ secretin embedded in the outer membrane. The assembled complex of PilQ is a 12-14mer with a $60 \AA$ diameter hole in the center, through which the pilus fiber can pass (Bitter et al. 1998; Collins et al. 2001; Collins et al. 2004; Frye et al. 2006). Absent a fiber, the hole in the assembled PilQ is closed at both ends. When a pilus fiber, growing up from its base in the inner membrane, pushes the channel gate open, the pilus is allowed to pass through the $60 \AA$ hole. Then, PilQ acts like a sealed bushing that surrounds the pilus as it elongates or retracts.

Type IV pili are polarized; they are found only at one pole of M. xanthus rod-shaped cells (Kaiser 1979; Wu et al. 1997). When the PilQ

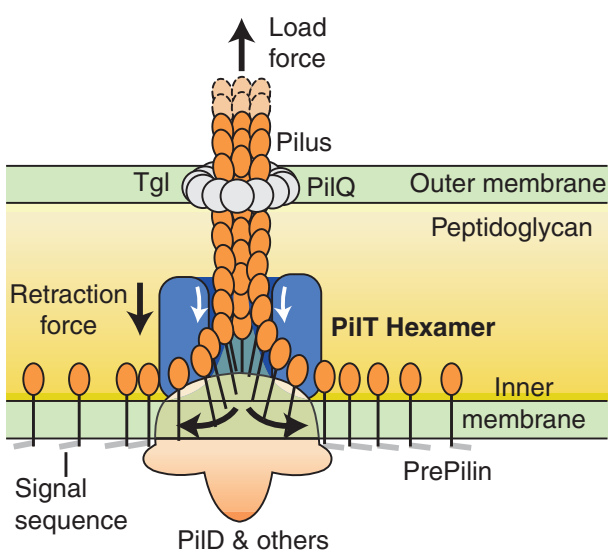

Figure 3. Type IV pilus engine. Tgl is an outer membrane lipoprotein. PilQ is the secretin protein. Once the pilus tip has attached to polysaccharide fibrils on cells ahead, PilT, a AAA ATPase causes the pilus fiber to retract. (Reprinted, with permission, from Kaiser 2008b [Annual Reviews].) 
protein is extracted from whole cells by exposing them to a hot detergent solution, roughly half of the PilQ protein is extracted as $98 \mathrm{kDa}$ monomers; the other half as high molecular weight, detergent-resistant multimers (Nudleman et al. 2006). Nudleman et al. found that multimer assembly requires $\mathrm{Tgl}$, a $17 \mathrm{kDa}$ outer membrane lipoprotein in M. xanthus (Table 1). Tgl is necessary for the production of pili in $M$. xanthus, and it is the only required pilusassociated protein whose gene resides outside the pil gene cluster (Rodriguez-Soto and Kaiser 1997a; Rodriguez-Soto and Kaiser 1997b). The primary translation product of the $t g l$ gene has a signal peptidase II recognition sequence for outer membrane lipoproteins, and processed Tgl protein is found in the outer membrane (Simunovic et al. 2003). Beyond the signal peptidase recognition site, the Tgl amino acid sequence comprises six tetratrico peptide repeats (TPRs). TPR sequences are found in many proteins that assist the assembly of multiprotein complexes, and each TPR has the capacity to form an $\alpha$-helix (D'Andrea and Regan 2003). Most likely the 6 TPR helices bring adjacent PilQ monomers into such close apposition that the resulting assembly resists dissociation in heated detergent. The integrity of the PilQ oligomers depends on the molecular integrity of Tgl. This role of Tgl finds support in the fact that $\mathrm{Tgl}$ can be exchanged by contact between cells, allowing one cell to stimulate the motility of another (Nudleman et al. 2005).

Immunolocalization experiments show that all of the PilQ molecules occur within a single large polar condensate (Nudleman et al. 2006). Condensation to a single focus implies that PilQ monomers associate with each other and perhaps with other Pil proteins in the outer membrane. However, the structures of the PilQ condensations at opposite ends of a cell differ from each other. One condensation is derived from the end that lacks pili: Those PilQ monomers are not assembled, but they are clustered. The other condensation includes several open secretin channels, each of which surrounds a single pilus fiber. Each pole has approximately half of the PilQ from whole cells (Nudleman et al. 2006). From the piliated cell ends, detergent-resistant PilQ multimers and $\mathrm{Tgl}$ are found. From the condensation at a nonpiliated end, PilQ would be extracted by detergent as unassembled $98 \mathrm{kDa}$ monomers.

PilT, an AAA ATPase, is the motor for pilus retraction. Its structure has recently been solved (Satyshur et al. 2007), and three different monomer structures were evident in the crystalline hexamers of PilT. Those structures imply that PilT changes its conformation during retraction. M. xanthus PilT has been shown to develop more than $110 \mathrm{pN}$ of tension during retraction (Maier et al. 2002). Retracted pilin monomers are stored in the inner membrane for reuse by PilB, another AAA ATPase found in the inner membrane that catalyzes fiber extension (Table 1).

Refering to Figure 3, what is it that keeps unassembled PilQ monomers together in a cluster at the nonpiliated pole in such a way that it can later assemble oligomers? The answer, we suggest, is a pilus-like organelle that lacks a pilus fiber. That organelle would include PilB, PilM, PilN, PilO, and PilT proteins that localize to the inner membrane and to the periplasm. Its existence is supported by the observation that PilB and PilT are bipolarly localized in $P$. aeruginosa whereas the PilU protein and the assembled pili are strictly unipolar (Chiang et al. 2005). Such an organelle would have to pass through the peptidoglycan meshwork, because PilQ is found in the outer membrane whereas PilB and PilT are in the inner membrane. The organelle would thus pierce, with an opportunity to join to, the rigid sacculus (Bui et al. 2009), which the PilB and PilT motors could use as a fulcrum. Also because the structure pierces the rigid peptidoglycan meshwork, its position would be fixed within the cell, and the associated PilQ monomers would not be expected to diffuse laterally in the membrane. Neither Tgl nor PilA would be part of the structures at the nonpiliated pole; both would be added at the time and place of secretin and pilus assembly. The precursor organelle, capped with a patch of unassembled PilQ, could reside at the nonpiliated pole, waiting for $\mathrm{Tgl}$ (and other proteins such as FrzS) to 
Myxobacteria, Polarity, and Multicellular Morphogenesis

induce assembly of the PilQ monomers and for a pilus filament to grow through the PilQ channel.

\section{A Motility}

Two different mechanisms have been proposed for A motility. First, polysaccharide slime secretion through the hundreds of nozzles that are found clustered at the poles of each cell was observed. Many electron micrographs and light micrographs show slime extrusion from one cell pole in wild-type cells (Wolgemuth et al. 2002; Yu and Kaiser 2007). A time-lapse movie shows the moment-by-moment correlation between the deposition of a slime trail onto agar and the forward movement of the lagging cell pole, where the nozzles extruding slime are located (Kaiser 2008b). A trail of extruded polysaccharide gel sticks to an agar gel (binding to agarose in the gel), and secretion elongates the bound polysaccharide (Kaiser 2009). The higher concentration of saccharides found in the trail than in a $1 \%$ agar gel renders the trail visible in phase-contrast microscopy. Biochemical-genetic studies of the nozzles reveal their structural and functional similarity to the pores from which group 1 and 4 capsular slime is secreted from E. coli (Kaiser 2009; Whitfield and Roberts 1999; Yu and Kaiser 2007). Slime secretion has been specifically associated with A motility, and not with S motility (Fontes and Kaiser 1999).

A second mechanism was recently proposed-one associated with focal adhesions that contain the AglZ protein (Mignot et al. 2007). The focal adhesions are periodically distributed along the line of cell contact with the substrate, usually agar as mentioned. The focal adhesions are reported to be spaced at roughly $2-\mu \mathrm{m}$ intervals; they first appear in the front half of the cell; then migrate toward the lagging pole as the cell moves forward (Mignot et al. 2007). Others reported that AglZ is a cytoplasmic protein with a regulatory function rather than a cell surface protein with motor function as had first been thought (Mauriello et al. 2009a; Mauriello et al. 2009b). Nevertheless, AglZ is an A motility protein (Yang et al.
2004), though nonessential (Mauriello et al. 2009b).

Instead of collaborating with the laterally arrayed engines just proposed, focal adhesions might facilitate propulsion by polar slime secretion. In particular, adhesions could relieve the elastic stress that is expected in a gel, consisting of capsular slime and LPS, interfacing a gliding cell with its agar substratum, by the mechanism proposed in Figure 3 of (Kaiser 2009). Because the interfacial gel adheres to the cell surface on one side and to the agar on the other, the gel would be deformed as the gliding cell moves relative to the agar. Myxococcus gliding on agar is relatively slow, about $4 \mu / \mathrm{min}$ (Kaiser and Crosby 1983), and the interfacial gel is viscous because of the high density of polysaccharide chains. Consequently the Reynolds number for movement is about $10^{-5}$. As outlined by (Purcell 1977), the mechanical behavior of cells at very low Reynolds number is dominated by the viscous forces: Momentum can play no role. One cannot move forward by walking in thick tar, for example. Accordingly, the motion of a cell that is pushed forward by secretion from its lagging end would create viscoelastic stress in the interfacial gel layer located between the cell and the agar, as described (Kaiser 2009). Because one surface of the interfacial gel adheres to the cell whereas the other surface adheres to the agar, there is no slip on either side. The resulting viscoelastic stress would consist of stretching the formerly relaxed and compressed polysaccharide chains in the direction of cell movement, and such stress would oppose the cell's forward motion, as pointed out by Purcell (Purcell 1977). However, each focal adhesion, by rigidly connecting the cell to the agar, and remaining for a limited time, would permit the stress that had accumulated next to the adhesion to dissipate. As the stretched polysaccharide chains diffuse, and spontaneously re-compress, stress energy would be dissipated as heat. Once a cell has been pushed forward by slime secretion from its lagging end, a new, more forward adhesion can form within the gel interface that walls-off a new section of the gel for stress relief. Such a role would explain why there are several focal adhesions (to wall 
D. Kaiser, M. Robinson, and L. Kroos

off the stressed gel, section by section), and why the adhesions are transient and rapidly lost as the cell moves forward (once the stress has dissipated, the adhesion will have served its purpose). In this view, focal adhesions would serve as escapements that permit the cell to move forward smoothly throughout a full reversal period. In conclusion, the two types of engines differ in their cellular location as described. The polar engines are permanent parts of the cell whereas the focal adhesions are transient parts. Finally the two mechanisms use different molecular engines: The polysaccharide gel expands as water binds to its sugar residues, and expansion provides force; protein parts of the focal adhesions that generate force are still being sought.

\section{SWARMING}

Myxobacteria grow while they actively spread over a solid surface from which they are receiving nutrient. Called swarming, the process directs moving cells to the very edge of the swarm, where there are few cells and hence less competition for nutrients. In the swarm center, cells compete for nutrient from below and for oxygen from above; competition limits the growth rate (Kaiser 2007). The roughly 50 species of Myxobacteria form flat spreading swarms on agar. Swarm cells are in constant motion and are interacting with each other (Reichenbach 1984; Stanier 1942). Swarms of M. xanthus are large compared with colonies, relatively thin, and resemble an egg fried overeasy. A swarm, pictured in Figure 4, lacks the sharp edge, the heaped center, and the dome shape of a nonswarming $E$. coli colony on agar or a nonswarming $M$. xanthus $m g l$ mutant (Kroos et al. 1988). Figure 5 shows the very edge of a swarm of $M$. xanthus at a higher magnification, revealing individual cells, slime trails, and various kinds and sizes of cell clusters, all of which are dynamic. Because of their low density, the cells at the swarm edge should have unfettered access to oxygen and nutrients, and to be able to eliminate their wastes readily. Consequently, they should be able to grow there at maximum rate without entering stationary

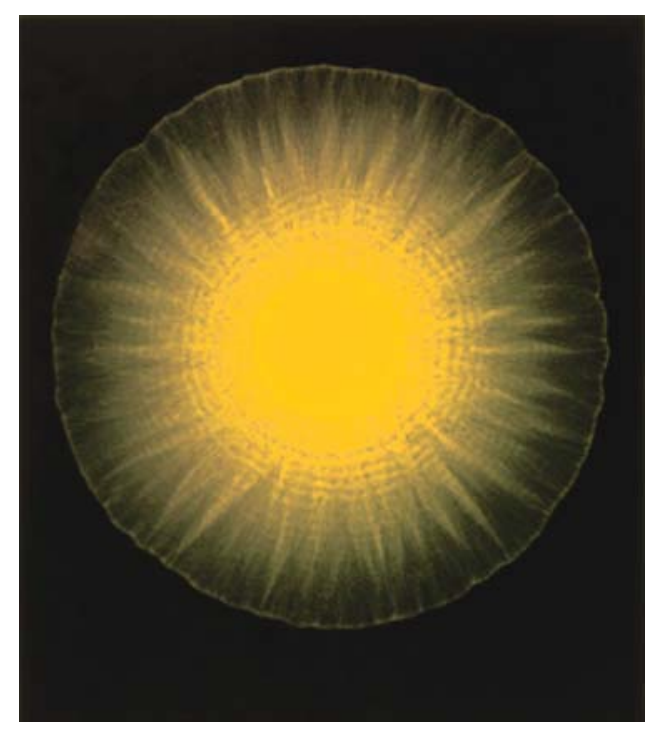

Figure 4. A swarm of Myxococcus xanthus, strain DK1622, on agar. Photo taken by Dr. Lotte Jelsbak after incubation at $32{ }^{\circ} \mathrm{C}$. The center of the swarm has several layers of cells. At the edge of the swarm, a single layer of single cells and lateral clusters of cells are spreading outward. Slightly higher cell densities over their surroundings are indicated by the rings and spokes. (Reprinted, with permission, from Jelsbak and Kaiser 2005 [ (C) ASM].)

phase, as long as fresh surface is available. Swarming depends on a strategy of random movement of long, flexible cells constrained to avoid collision with each other (Kaiser 2007). Net movement within a swarm is in the radial direction and that leads to swarm expansion. A technique used by $M$. xanthus to avoid collisions is similar to one used by pedestrians moving in opposite directions that spontaneously organize traffic lanes to slip past one another. Another behavior used by Myxococcus to promote swarming is periodically to reverse their gliding direction to recover from collisions that are unavoidable in high-density populations.

As described earlier, M. xanthus uses both polar type IV pili (S motility) and polar slime secretion (A motility) for their swarming movements, and the distantly related myxobacterium, Sorangium cellulosum, has genes for both these gliding engines (Schneiker 2007). 
Myxobacteria, Polarity, and Multicellular Morphogenesis

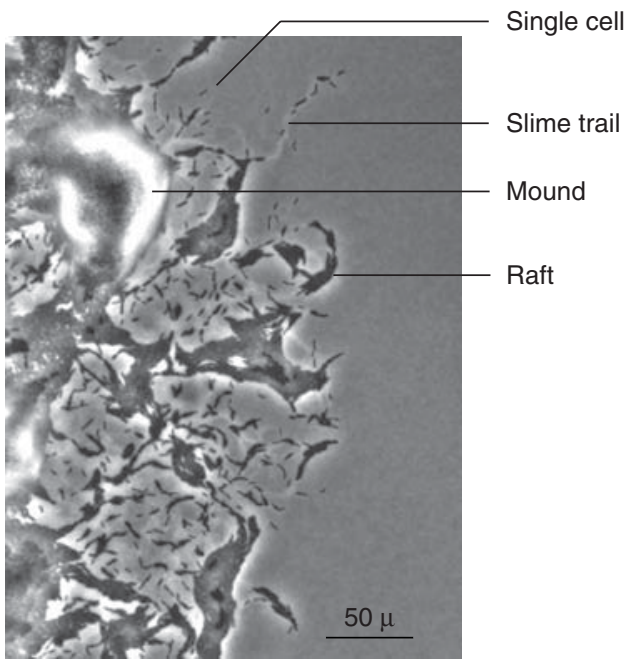

Figure 5. Distribution of cells and multicellular structures at the swarm edge. In addition to some individual cells and slime trails, multicellular rafts and multicellular mounds are labeled. The swarm is expanding in the radial direction, which is to the right in this image. (Scale bar, $50 \mu$ ). (Reprinted, with permission, from $\mathrm{Wu}$ et al. 2009 [National Academy of Sciences].)

Genetic studies of $M$. xanthus motility began with the isolation of mutants that produced abnormal swarms (Burchard 1970). Jonathan Hodgkin showed that the $\mathrm{A}$ and $\mathrm{S}$ engines are encoded by different gene sets (Hodgkin and Kaiser 1979a; Hodgkin and Kaiser 1979b). More than 50 double mutants, having one mutation in an A engine component and one mutation in an S engine component, were constructed, and they all failed to swarm (Hodgkin and Kaiser 1979b). By contrast, many single mutations in $m g l A$, which had no effect on growth measured in suspension culture, also blocked swarming. Wild type and other single motility mutants do swarm, showing that either engine alone can support swarming. MglA mutants were common among Hodgkin's early isolates, and because they cannot swarm, their colonies have a sharp edge and a heaped center much like the colonies of nonswarming E. coli (Hodgkin and Kaiser 1979b).

Thirty years and several hundred new motility mutations later, MglA protein remains outside the set of protein components belonging to the $\mathrm{A}$ or the $\mathrm{S}$ engines. The $\mathrm{A}$ engine in an mglA mutant was shown to be capable of polar slime secretion ( $\mathrm{Yu}$ and Kaiser 2007). The microscopic and genetic studies of Rosa Yu show that MglA is needed to switch both engines from one cell end to the other. Whereas all of her motile strains produced slime only at one end of each cell at any instant, $m g l A$ mutants secreted slime from both cell ends (Yu and Kaiser 2007). All A motile strains can produce slime from either end, and they switch the producing end when they reverse gliding direction; evidently $m g l A$ mutants fail to switch ends. Studies of single mutant $S$ motile strains $\left(\mathrm{A}^{-} \mathrm{S}^{+}\right)$show that they are able to produce pili from either pole and that their pili do switch poles when cells reverse their gliding direction (Hartzell et al. 2008). Bipolar slime secretion in $m g l A$ mutants (which fail to switch) suggest that by trying to move in both directions simultaneously, the mutant cells are unable to make progress in either. This view of bipolar secretion explains Spormann's observation that mutant $m g l A$ cells are, in fact, oscillating very rapidly back and forth while moving less than $1 / 5$ of a cell length in either direction, which would account for their sharp colony edge (Spormann and Kaiser 1999). Yu, Kaiser, and Wolgemuth suggested that these rapid oscillations are not because of signals from the reversal generator but arise from the normal statistical fluctuations in the number of active slime secretion nozzles at the two poles. Fluctuations are significant because relatively few slime filaments are observed (of order 10) at each slime-secreting end of wild-type cells (Wolgemuth et al. 2002). The speed of $\Delta m g l B$ cells, which have partial A motility ( $\mathrm{Yu}$ and Kaiser 2007), is observed to fluctuate from 1 to $>5.5 \mu \mathrm{m} /$ minute (Spormann and Kaiser 1999), and these fluctuations can be explained by variations in the number of active nozzles. According to this statistical hypothesis, the speed distribution of $\Delta m g l A B$ double mutant cells should be the difference between the speeds of two independent $\Delta m g l B$ ends. Agreement between the observed and the speeds predicted (calculation by C. Wolgemuth) by the statistical hypothesis, as reported (Kaiser 2008a), supports the 
hypothesis that the rapid reversals are a consequence of active slime secretion from both ends that are unable to switch.

\section{Maintaining Engine Polarity}

Both the $\mathrm{A}$ and the $\mathrm{S}$ engines are inherently polar in that they are able mechanically to produce force in one direction only: Pili only when they retract and slime only when it pushes. Comparative measurements of the rate of swarm expansion show that the $\mathrm{A}$ and the $\mathrm{S}$ engines on each cell have the same polarity (Kaiser and Crosby 1983). Under controlled conditions, a swarm, such as that shown in Figure 5, will spread outward on agar at a constant rate for many days (Burchard 1974; Kaiser and Crosby 1983). The increasing diameter of the swarm largely reflects active cell movement, because the colony of an $\mathrm{A}^{-} \mathrm{S}^{-}$mutant, which has defects in both engines, expands, because of cell growth and division, at less than $1 / 8$ the rate of $\mathrm{A}^{+} \mathrm{S}^{+}$swarms (Kaiser and Crosby 1983). Together, the two engines in $\mathrm{A}^{+} \mathrm{S}^{+}$cells promote swarming at $1.6 \mu \mathrm{m} / \mathrm{min}$, almost 3 times the rate of cells that have one or the other engine alone ( 0.6 or $0.4 \mu \mathrm{m} / \mathrm{min}$ ) (Kaiser and Crosby 1983). Indeed, the maximum swarming rate of $\mathrm{A}^{+} \mathrm{S}^{+}$is $60 \%$ greater than the sum of the two single engine rates (1.6 versus $0.6+0.4$ $\mu \mathrm{m} / \mathrm{min})$. This synergism implies that the two engines are always arranged so as to move a cell in the same direction, and are positioned at opposite ends of the cell: The pulling pili at the leading pole of the cell and the pushing A engines at the trailing pole. This has been confirmed experimentally (Leonardy et al. 2008). The increase in swarm rate with initial cell density shows that individual cells cooperate with each other to swarm; an increase is seen both with A motility and with S motility (Wu et al. 2007; Wu et al. 2009).

The maintenance of polarity when cells divide reveals a template in each cell that is needed when the division septum creates two new cell ends. Observing the several hundred isolated cells at the edge of the $\mathrm{A}^{+} \mathrm{S}^{+}$swarm in the published movie (Wu et al. 2009), it became apparent that both daughter cells were able to move as soon as they had separated from each other. Each daughter inherits one of her mother's engines and it must assemble new engines for its new pole. A structure that will be called the polarity template ensures that each daughter assembles the correct engine at its new pole so that a daughter always emerges with pili at its front and slime secretion at its back. The molecules that constitute the template remain to be identified, but they appear to include the peptidoglycan sacculus (Bui et al. 2009), the outer membrane at both poles, the inner membrane at both poles, and the engine rudiments at both poles. Whatever its chemical composition, the template cannot demand, "Construct a pilus engine at this pole." Or "Construct a slime engine at that pole." Template instructions must allow for the fact that all cells, including newborn cells, will reverse their gliding direction within a few minutes after birth (Blackhart and Zusman 1985a). The reversal period (of order 10 minutes) is much shorter than the generation time (roughly $31 / 2$ hours in rich medium at $32^{\circ} \mathrm{C}$.); for that reason reversal is not likely to be linked to cell division or to the cell cycle (Wu et al. 2009). Many reversals can also be seen in Reichenbach's movies of the swarming of several different myxobacterial species (Kuhlwein and Reichenbach 1968). Individual cells alternate between gliding in one or the other direction along their pole-to-pole axis. Finally, observation of isolated single cells reversing (Kaiser 2007) as well as the tracks of many cells at higher density (Jelsbak and Søgaard-Andersen 2002), it was concluded that cells stop momentarily before moving off in the opposite direction. When cells do reverse, head and tail switch within roughly a minute; both engines and both ends appear to be switched simultaneously.

\section{Reversing the Engines}

Although each engine includes more than 15 different proteins (Table 1 and Table 2), relatively few of those proteins are directly involved in the coordination of pole switching. At each pole, multiple copies of only one type of engine (either the A engine or the $\mathrm{S}$ engine) are 
Myxobacteria, Polarity, and Multicellular Morphogenesis

Table 2. A motility genes

\begin{tabular}{|c|c|c|c|c|}
\hline Gene location $^{\mathrm{a}}$ & $\begin{array}{l}\text { Gene } \\
\text { name }\end{array}$ & $\begin{array}{l}\text { Phenotype of } \\
\text { knockout mutant }\end{array}$ & Protein domain function(s) & COG\#, cd\#, or Ref. \\
\hline MXAN1925 & $m g l A$ & Nonmotile $\left(\mathrm{A}^{-} \mathrm{S}^{-}\right)$ & Raslike small GTPase & COG1100 \\
\hline MXAN2541 & $\operatorname{aglAR}$ & No A-motility & unknown & None \\
\hline MXAN3008 & $\operatorname{agl} U$ & No A-motility & $\begin{array}{l}\text { WD-repeat lipoprotein, } \\
\text { acylaminoacyl-peptidase }\end{array}$ & COG1506 \\
\hline MXAN3536 & $\operatorname{aglZ}$ & Cond $^{\mathrm{c}}$ A-motile & $\begin{array}{l}\text { Receiver domain, coiled-coil, } \\
\text { regulatory protein }\end{array}$ & Mauriello, 2009 \\
\hline MXAN3060 & $\operatorname{cglB}$ & Compl $^{\mathrm{d}}$ A-motility & $\begin{array}{l}\text { Outer membrane lipoprotein, } \\
\text { stimulatable }\end{array}$ & $\operatorname{cd} 01456$ \\
\hline MXAN2538 & $\operatorname{cglC}$ & Compl $^{\mathrm{d}}$ A-motility & $\begin{array}{l}\text { Outer membrane lipoprotein, } \\
\text { stimulatable }\end{array}$ & \\
\hline MXAN0962 & $c g l D$ & Compl $^{\mathrm{d}}$ A-motility & $\begin{array}{l}\text { Outer membrane lipoprotein, } \\
\text { stimulatable }\end{array}$ & \\
\hline MXAN4866 & $\operatorname{cglE}$ & Compl $^{\mathrm{d}}$ A-motility & $\begin{array}{l}\text { Outer membrane lipoprotein, } \\
\text { stimulatable }\end{array}$ & D. Wall, unpubl. \\
\hline MXAN4868 & $\operatorname{cglF}$ & Compl $^{\mathrm{d}}$ A-motility & $\begin{array}{l}\text { Outer membrane lipoprotein, } \\
\text { stimulatable }\end{array}$ & D. Wall, unpubl. \\
\hline MXAN4862 & $\operatorname{agm} X$ & No A-motility & Outer membrane lipoprotein & COG2885 \\
\hline MXAN4863 & $\begin{array}{l}\operatorname{agmK} \\
\operatorname{agnA}\end{array}$ & No A-motility & $\begin{array}{l}\text { TPR repeat protein } \\
A B C \text { transporter component }\end{array}$ & COG0457 \\
\hline MXAN6403 & $\begin{array}{l}\operatorname{agn} B \\
\operatorname{agn} C\end{array}$ & No A-motility & $\begin{array}{l}\mathrm{ABC} \text { transporter permease protein } \\
\mathrm{ABC} \text { transporter component }\end{array}$ & COG4591 \\
\hline MXAN7296 & $a g l C R$ & No A-motility & unknown & None \\
\hline MXAN1926 & $m g l B$ & Partial A-motile & $\begin{array}{l}\text { Roadblock/LC7 exchange factor } \\
\text { for MglA }\end{array}$ & NOG46155 \\
\hline MXAN2050 & pglH & Partial A-motile & $\begin{array}{l}\text { TPR repeat, CheY-like receiver } \\
\text { domain, and a DNA-binding } \\
\text { domain }\end{array}$ & COG0745, Yu, 2007 \\
\hline MXAN2919 & $p g l J$ & Partial A-motile & Polysaccharide polymerase & COG3307, Yu, 2007 \\
\hline MXAN2921 & $p g l B$ & Partial A-motile & Glycosyl transferase, RfaG & COG0438, Yu, 2007 \\
\hline MXAN4148 & $p g l K$ & Partial A-motile & $\begin{array}{l}\text { Transmembrane protein of } \\
\text { unknown function }\end{array}$ & COG5662, Yu, 2007 \\
\hline MXAN4616 & $\operatorname{pglF}$ & Partial A-motile & Glycosyl transferase & COG0463, Yu, 2007 \\
\hline MXAN4710 & pglN & Partial A-motile & $\begin{array}{l}\text { ADP-heptose synthase, } \\
\text { bifunctional sugar kinase/ } \\
\text { adenylyltransferase }\end{array}$ & COG2870, Yu, 2007 \\
\hline MXAN4867 & $p g l I$ & Partial A-motile & unknown & Yu and Kaiser 2007 \\
\hline MXAN5319 & $p g l C$ & Partial A-motile & TPR repeat & COG0457, Yu, 2007 \\
\hline MXAN5382 & aspT & Partial A-motile & tRNA-Asp & Yu and Kaiser 2007 \\
\hline MXAN5585 & $p g l E$ & Partial A-motile & $\begin{array}{l}\text { 4-amino-4-deoxy-L-arabinose } \\
\text { transferase }\end{array}$ & COG1807, Yu, 2007 \\
\hline MXAN6501 & pglD & Partial A-motile & GDP-mannose pyrophosphorylase & COG0836, Yu, 2007 \\
\hline MXAN6607 & $\operatorname{agmT}$ & Partial A-motile & unknown & COG1559 \\
\hline MXAN7160 & pglM & Partial A-motile & Alanine racemase & COG0787, Yu, 2007 \\
\hline MXAN7252 & $p g l A$ & Partial A-motile & $\begin{array}{l}\text { Exopolysaccharide synthesis, } \\
\text { ExoD-like }\end{array}$ & COG3932, Yu, 2007 \\
\hline
\end{tabular}

${ }^{a}$ MXANxxxx (Goldman et al. 2006); COG, conserved orthologous group in NCBI database; cd, conserved domain in NCBI database. Ref., publication

${ }^{\mathrm{b}} \mathrm{NOG}=$ non supervised orthologous group in STRING database (http://string.embl.de/;

${ }^{\mathrm{c} C o n d}$., Conditionally A motile.

${ }^{\mathrm{d}}$ Compl. $=$ Complementable by cell end-to-end contact (Hodgkin and Kaiser 1977). 
observed: Switching resembles a cooperative change from one physicochemical phase to another, each composed of similar sets of molecules and having only slightly different structures. As mentioned, wild-type cells reverse at roughly 10-min intervals (Blackhart and Zusman 1985a; Mignot et al. 2005). Yu showed that wild type and $p g l$ mutants have the same reversal frequency but different cell speeds ( $\mathrm{Yu}$ and Kaiser 2007). Each frizzy mutant of M. xanthus inherits a well-defined average frequency of gliding reversal (Astling et al. 2006). Among frzCD mutants, the frequency can be higher or lower than wild type (McBride et al. 1992). The frz system encodes a cytoplasmic circuit that controls the frequency of reversal of gliding direction (Blackhart and Zusman 1985a). Frizzy proteins are related by amino acid sequence to chemosensory proteins (Bustamante et al. 2004). Although the methylaccepting-chemotaxis-proteins (MCPs) of $E$. coli are membrane receptors, FrzCD, the MCP homologue in the frz system resides in the cytoplasm (Mauriello et al. 2009b; McCleary et al. 1990). FrzCD lacks transmembrane and extracellular domains, and its amino-terminal domain has no similarity to the $\mathrm{N}$-termini of chemotaxis MCPs (Bustamante et al. 2004). These differences indicate that the role of the frizzy proteins is probably not chemotaxis. FrzE is signaled by FrzCD and it has one domain homologous to a cheA histidine protein kinase and a second response regulator domain (Acuna et al. 1995). FrzE catalyzes its own phosphorylation and transfers that phosphate to its response regulator domain (Acuna et al. 1995; McCleary and Zusman 1990a; McCleary and Zusman 1990b). Although wild-type cells reverse at 8.8 -min intervals, a frzE null mutant has a long reversal period. A mutant that lacks the carboxyterminal end of FrzCD, reverses at 2-min intervals, as if methyl-FrzCD induces the phosphorylation of FrzE (Blackhart and Zusman 1985b). These observations suggest that a critical level of FrzE $\sim \mathrm{P}$ could be the signal to reverse gliding direction.

The role played by the frizzy system in swarming, where it is known to regulate the reversal frequency (Blackhart and Zusman 1985a), was discovered by Oleg Igoshin. Although Igoshin was investigating production of the traveling waves that are prominent early in aggregation for fruiting body development, he found it necessary to introduce negative feedback from FrzE $\sim P$ back onto the methylation of FrzCD (Igoshin 2004). He proposed that FrzE $\sim P$ inhibited the methylation of FrzCD, catalyzed by FrzF, rather than enhancing demethylation, catalyzed by FrzG (Igoshin et al. 2001). The resulting negative feedback loop would cause the levels of FrzE $\sim \mathrm{P}$ and of MeFrzCD to oscillate out of phase with each other. Dubbed the "Frizilator", the circuit has the necessary refractory period (Igoshin et al. 2001) and the necessary time delay (Börner et al. $2002)$ to sustain regular oscillations. The frizilator circuit has been corroborated by quantitative studies of the reversal periods and the swarm expansion rates of frizzy gene deletion mutants (Wu et al. 2009; Kaiser D, unpubl. data). Although the Frizilator was discovered in cultures that were developing fruiting bodies, similar oscillations occur in cultures that are growing, swarming, and not yet capable of developmental signaling, which must be induced by starvation. The Frizilator circuit makes up the right-hand side of Figure 6.

\section{MgIA is Switched by the Frizilator}

As mentioned, Rosa Yu observed that MglA mutants, known to be defective in both A motility and S motility, were secreting slime from both ends of its cells (Yu and Kaiser 2007). Unipolar slime secretion is essential for significant cell movement, and bipolar secretion stops $\mathrm{A}$ motility (Yu and Kaiser 2007). MglA is a G-protein that belongs to the extended Ras-like family of small GTPases (Hartzell and Kaiser 1991a); the crystal structure of HRAS has been solved (Holbrook and Kim 1989; Pai et al. 1989). In $M$. xanthus and many other prokaryotes, $m g l A$ is part of a two gene operon with $m g l B$, a regulator that belongs to the Roadblock/LC7 group (Koonin and Aravind 2001). MglA protein is unstable in a $\triangle m g l B$ mutant (Hartzell and Kaiser 1991b) as if MglA is prone to degradation, unless MglB is associated with it. 
Myxobacteria, Polarity, and Multicellular Morphogenesis

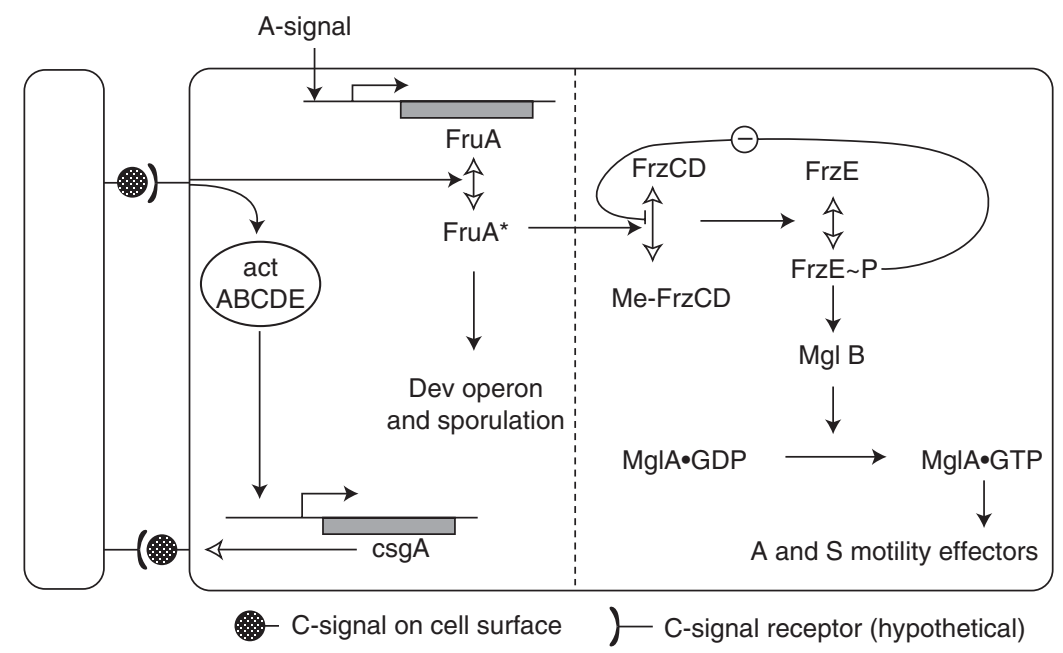

Figure 6. The Frizilator and the reversal generator are shown to the right of the dashed vertical line. That circuit is always active and it regulates swarming. The C-signal, which appears shortly after starvation induces fruiting body development, is a $17 \mathrm{kDa}$ cell surface protein. Cells must make end-to-end contact with each other to transmit the signal. The C-signal transduction pathway is shown to the left of the dashed vertical line. FruA, a response regulator, that has been activated by $\mathrm{C}$-signaling is symbolized FruA*. It may include FruA $\sim \mathrm{P}$.

It is proposed that the response regulator domain of FrzE $\sim \mathrm{P}$ activates the MglAB complex to generate $\mathrm{MglA} \bullet \mathrm{GTP}$, as shown in Figure 6. This proposal is analogous to the activation of the flagellar switch complex in enteric bacteria by $\mathrm{CheY} \sim \mathrm{P}$ (Stock et al. 1995). Both FrzE (McCleary and Zusman 1990b) and MglA proteins (Hartzell and Kaiser 1991a) are found in the cytoplasm where they are able to interact with each other, and where $\mathrm{MglA} \bullet \mathrm{GTP}$ can be formed. Recent studies of reversal during swarming suggest that $\mathrm{MglAB}$ by itself is an oscillator whose natural period is about $34 \mathrm{~min}$ (Wu et al. 2009). We suggest further that the Frizilator evolved to entrain the MglAB oscillator to obtain an optimal reversal period in the range of 7-9 min, which relates to the observed cell speed of $4 \mu \mathrm{m} / \mathrm{min}$ (Wu et al. 2009).

\section{Motility Effectors of MgIAB}

Reversal involves effectors of MglAB specific for A motility and other effectors specific for $\mathrm{S}$ motility, to switch both engines following instructions from the template. As mentioned, switching engines from one pole to the other is all or none: At either pole of the cell all the active engines are either for A motility or for $\mathrm{S}$ motility (type IV pili), and mixtures of different active engines do not seem to occur. As indicated in Figure 6, mutual exclusion between engines is enforced by the effector proteins that are directly regulated by the MglAB switch, usually as a result of protein-protein contact. Effector activity is graded and regulates the timing of engine assembly. Effector RomR, which is essential for A motility, is a phosphorylated response regulator. RomR protein forms clusters at both cell poles, but the cluster at the lagging pole of the cell is larger than the cluster at the leading pole (Leonardy et al. 2007). Moreover, the larger cluster switches from one pole to the other in parallel with the cell's reversal of gliding direction (Leonardy et al. 2007). Thus, at every instant, the larger cluster is found at the cell pole that is believed to be actively secreting slime, and correlating RomR $\sim \mathrm{P}$ with slime secretion. The dynamic re-localization of RomR was shown to depend on the Frz system as well as on the Mgl switch (Leonardy et al. 2007). Perhaps RomR is phosphorylated by the 
M. xanthus Wzb and Wzc homologs (Kaiser 2008b), which are known to encode an autokinase/phosphatase that regulates capsule secretion in E. coli (Paiment et al. 2002; Wugeditsch et al. 2001).

The AglZ protein is another effector of A motility. MglA has been found to interact physically with AglZ protein in a yeast two-hybrid experiment with MglA as the bait (Yang et al. 2004). The amino-terminal 120 amino acids of AglZ is a pseudoreceiver, CheY-like domain that has been found to interact with purified MglA protein in vitro (Yang et al. 2004). The same domain of AglZ interacts with FrzCD protein in cytoplasmic clusters that lie on a helix and span the cell length (Mauriello et al. 2009b). Where the helix intersects a line drawn along the bottom of the cell, the AglZ-FrzCD clusters generate the focal adhesion sites described by Mignot et al. 2007.

$\mathrm{CglB}$ protein is also involved in switching A engine polarity, most likely as an effector. CglB was shown by Hodgkin to be essential for A motility and to play no role in S motility (Hodgkin and Kaiser 1979b), as is the case for RomR and AglZ. CglB is a lipoprotein with a type II signal sequence (Rodriguez and Spormann 1999) that resides in the outer membrane (Simunovic et al. 2003). Yu observed that mutants lacking CglB simultaneously secrete slime from both its ends, as if CglB normally prevents slime secretion from the nozzles found at the leading pole ( $\mathrm{Yu}$ and Kaiser 2007). Mutant $\operatorname{cglC}, \operatorname{cglD}, \operatorname{cglE}$, and $\operatorname{cglF}$ (Table 2) have motility phenotypes similar to that of cglB (Hodgkin and Kaiser 1977). Moreover, several other A motility genes whose mutants have a bipolar secretion phenotype (Yu and Kaiser 2007) may also be effectors, although a direct interaction with $\mathrm{Mgl}$ has not been shown. Also preventing bipolar secretion (and included in Table 2), AglU and AgmX are both lipoproteins, whereas AgmK is a TPR protein (White and Hartzell 2000; Youderian et al. 2003); it thus resembles Tgl, a TPR protein known to be involved in protein assembly. The lipoproteinencoding genes $c g l E$, and $c g l F$ belong to an operon that includes agmX, agmK, and agmU, which encode other lipoproteins essential for
A motility (Table 2). Knockout mutants of $A g n B$, an $A B C$ transporter permease, or of AgnA, or of AgnC also show bipolar secretion (Yu and Kaiser 2007). The need for a large array of such proteins that prevent inappropriate slime secretion may be related to the tight coupling observed between polysaccharide polymerization and its secretion (Nesper et al. 2003). This array of regulatory proteins appears to inhibit nozzles at the leading pole from secreting until such time as the next reversal is ordered and those nozzles start to secrete. Despite their substantial numbers, there are fewer effectors than nozzle structural proteins; only those engine proteins that contribute to switching from end to end need have effectors. For instance, hundreds of nozzle orifices are always present at both cell ends (Wolgemuth et al. 2002); the orifices don't switch and have no need of effectors.

\section{S Motility Effectors of MglAB}

FrzS, which regulates $\mathrm{S}$ motility and not $\mathrm{A}$ motility (Ward et al. 2000), is an effector because it responds to the $\mathrm{Mgl}$ switch, although direct interaction of FrzS with MglA has yet to be shown. FrzS relocates between the cell poles in apparent synchrony with RomR, a well established effector (Leonardy et al. 2007). The function of FrzS can be inferred from the fact that a deletion mutant of FrzS has a lower rate of swarm expansion and a lower reversal frequency than the wild type, although the amount of lowering is less than a deletion of the FrzE gene (Ward et al. 2000). Neither the target nor the regulatory activity of FrzS have been found.

Assembled Tgl lipoprotein might be the regulatory target of FrzS, but if it isn't, then Tgl should be the target of some other S motility effector. The pilA gene, which encodes the pilin monomer, is one of the most highly transcribed genes in M. xanthus (Jelsbak and Kaiser 2005; Wu and Kaiser 1997). When the cell reverses direction, pili disappear from one pole and extend from the other. All the while, expression of the pilA gene has remained constant. As a general rule, effectors regulate protein localization both post-transcriptionally 
and post-translationally. Regarding its location in the cell, fluorescent Tgl (Nudleman et al. 2006), like FrzS (Ward et al. 2000), is only found at the leading cell pole. Pole specificity differentiates them from the majority of Pil proteins (Table 1) which are found constantly at both poles. Tgl and assembled PilQ differentiate the leading pole of the cell from the lagging pole that lacks pili, lacks Tgl, and lacks FrzS. Unassembled PilQ in the outer membrane appears to be held together at the pole in a single patch by attachment to the top of a cylindrical complex of proteins that includes PilG, PilM, PilN, PilO, and PilP (Nudleman et al. 2006). These proteins were identified by their requirement, together with PilQ, to transport new Tgl to the outer membrane where Tgl functions (Nudleman et al. 2006). These proteins are found in the periplasm and the inner membrane with PilB (Nunn et al. 1990). This multiprotein complex, which would extend from the outer membrane, penetrate the peptidoglycan mesh to enter the inner membrane; the complex is found fixed in position at both cell poles. Newly synthesized Tgl is able to link PilQ monomers together into a detergent-resistant complex as revealed by the stimulation phenomenon, although stimulation is not required for assembly (Nudleman et al. 2005). PilQ protein monomers are conserved, and they don't switch. Because assembled PilQ resists dissociation by $1 \%$ SDS at $100^{\circ} \mathrm{C}$ (Nudleman et al. 2005), it seems likely that Tgl is destroyed to allow the assembled PilQ to dissociate into a cluster of monomers. The process may resemble that found recently in Mycobacterium tuberculosis (Pearce et al. 2008), wherein a particular protein (Tgl in this case) would be marked and targeted for destruction by a protease. PopC (Rolbetski et al. 2008) is an activatable protease located in the outer membrane of $M$. xanthus. The protease-activating system, if triggered by MglA-GTP would be considered the effector for Tgl localization. Meanwhile newly synthesized Tgl that is not yet part of assembled PilQ would escape proteolysis by a membrane protease, as it is transported to the outer membrane where it assembles PilQ at the new leading pole (Kaiser 2008b). Thus it is suggested that a protein assembly, without a pilus fiber, with no Tgl protein, and probably with no FrzS is the product of $S$ engine inactivation. That assembly would await the addition of missing proteins to become an active pilus engine at the next polarity reversal.

\section{RESPONDING TO STARVATION BY BUILDING A FRUITING BODY}

M. xanthus has a single origin of bidirectional replication near the $d_{n a A}$ locus on its circular genome (Goldman et al. 2006). Using flow cytometry, Tzeng and Singer showed that a population of exponentially growing $M$. xanthus cells contain $1-2$ copies of the chromosome, indicating a single DNA replication initiation event per cell cycle and that cell division follows chromosome replication (Tzeng and Singer 2005). Tzeng and Singer showed further that, as cells approach the stationary phase, the initiation of DNA replication stops when all cells have one complete chromosome.

Before it reaches stationary phase, the culture faces a choice as its growth slows with nutrient limitation: It can stop growth entirely and initiate fruiting body development, or it can continue to grow, at what may be an everdecreasing rate dictated by the residual level of nutrient until the cells die. Because no more than $1 \%$ of the cells initiating fruiting body development become spores, and some cells prey on others, the majority of cells die whichever response is chosen. Because more than 30 new proteins must be made for aggregation and sporulation (Inouye et al. 1979), some capacity to synthesize proteins must be retained, and the population must start fruiting body construction before any essential nutrient has been totally depleted. Choosing between growing (probably with the hope of finding more nutrient soon) and fruiting body development is helped by a diffusible cell-to-cell signal, the A-signal (Figure 6). A-signal molecules, purified from medium conditioned by developing cells, proved to be a set of amino acids and peptides containing those amino acids (Kuspa et al. 1986; Kuspa et al. 1992a). Each Myxococcus cell that senses nutrient limitation and opts for 
development releases a small quantity of A-signal about two hours after it senses that starvation is immanent. Consequently the extracellular concentration of A-signal is directly proportional to the density of $M$. xanthus cells that have chosen development (Kaplan and Plamann 1996; Kuspa et al. 1992b). Cells in the population respond to A-signal only if its concentration is above a threshold. Cells respond by expressing a set of A-signal-dependent genes that include spi, csgA (the gene encoding C-signal), and fruA, an important developmental response regulator. A response to A-signal indicates that there are enough cells to complete one fruiting body: Those cells constitute a quorum that favors fruiting body development. Limitation for any amino acid, lack of carbon source, or too little phosphate induces $M$. xanthus to initiate fruiting body development (Manoil and Kaiser 1980a; Manoil and Kaiser 1980b). Neither the lack of purines nor of pyrimidines, which $M$. xanthus scavenges from prey nucleic acids, will induce development (Kimsey and Kaiser 1991). This suggests that a deficiency of any amino-acylated tRNA leads the population of cells to stop swarming and to initiate development. In M. xanthus as in many other bacteria, the absence or shortage of any one of the charged tRNAs leads a ribosome, sensing with a codon that lacks its cognate amino acylated tRNA, to synthesize guanosine tetra (and penta) phosphate, (p)ppGpp, in a reaction catalyzed by the relA synthase. The rise in (p)ppGpp sets off a stringent response that stops the synthesis of new ribosomes and of peptidoglycan (Cashel et al. 1996). In M. xanthus the stringent response also initiates expression of its developmentally regulated genes. Singer et al. showed that the accumulation of ( $\mathrm{p}$ )ppGpp was both necessary and sufficient to trigger fruiting body development (Singer and Kaiser 1995). In B. subtilis and in E. coli DNA synthesis is arrested by their stringent responses. By contrast, M. xanthus chromosome replication continues during development induced by the stringent response, and fruiting body myxospores contain two complete copies of the chromosome (Tzeng et al. 2006). A complete description of these processes can be found in (Diodati et al. 2008).
Aggregation for Fruiting Body Development

As discussed earlier, swarming cells reverse periodically triggered by the Frizilator. Reversals are essential for the swarm to spread outward as a thin sheet of cells, which provides them with greater access to nutrient. Reversals also help swarm cells build different kinds and sizes of multicellular structures: Rafts of adjacent cells that have their long axes parallel, and multilayered mounds that can be seen in Figure $5(\mathrm{Wu}$ et al. 2009). When (p)ppGpp arrests growth, outward spreading stops. Then cells migrate inward causing many traffic jams some of which become foci for aggregation (Kaiser and Welch 2004). Morphogenesis of M. xanthus fruiting bodies at the centers is directed by $\mathrm{C}$-signaling between cells. C-signal deficient mutants $(\operatorname{csg} A)$ were found to grow normally but not to aggregate or sporulate (Hagen et al. 1978; Kim and Kaiser 1990b; Shimkets et al. 1983). The Csignal is a $17-\mathrm{kDa}$ cell-surface-bound protein that communicates when pairs of cells make an end-to-end contact with each other (Kim and Kaiser 1990a; Sager and Kaiser 1994). The $\operatorname{csg} A$ gene encodes a $25 \mathrm{kD}$ protein that is secreted to the cell surface where it is cleaved to the active $17-\mathrm{kDa}$ signal (Lobedanz and Sögaard-Andersen 2003; Rolbetski et al. 2008). The complete C-signaling circuit shown in Figure 6 was worked out from the properties of gene knockout mutants that lack circuit elements, and more detail can be found in a recent review (Søgaard-Andersen 2008). The circuit includes the reversal generator that drives swarming and was discussed above. In addition to the frizilator's negative feedback, the circuit of Figure 6 includes two positive feedback loops. For this reason the circuit can have emergent properties, and development is the most important of these. Emergent properties can be extracted by computer simulation, and a continuous three-dimensional simulation (Sozinova et al. 2005; Sozinova et al. 2006) reproduces the experimentally observed stages of fruiting body formation: asymmetric initial aggregates (traffic jams), linear streams, formation of hemispherical mounds, and finally sporulation within the mounds. Although 
Myxobacteria, Polarity, and Multicellular Morphogenesis

the circuit of Figure 6 suffices to explain the sequence of stages, elements are missing, the Csignal receptor, for example.

\section{C-Signaling and Development}

As indicated in the figure, when traffic jams enlarge into fruiting bodies, C-signaling activates FruA, a developmentally important response regulator (Ellehauge et al. 1998). Simultaneously, expression of the C-signal is increased by a positive feedback loop involving the act operon (Gronewold and Kaiser 2001). Because of the positive feedback, there is a progressive increase in the cell surface level of Csignal. The five proteins of the act operon increase expression of the csgA gene (Gronewold and Kaiser 2007). At the start of development, there are few C-signal molecules per cell. Cells making end-to-end contact respond to signal exchange by reversing their direction of gliding which creates the traveling waves that are seen early in development (Welch and Kaiser 2001). One consequence of the feedback is that the waves are transient (Gronewold and Kaiser 2001). Each time C-signal is exchanged between cells in the crests of two colliding waves, the positive feedback loop increases expression of $\operatorname{csg} A$ and elevates the number of signal molecules on both signaling cells. The low initial level of C-signal found at the start of development produces a low level of activated FruA $\left(\right.$ FruA $^{*}$ ) that drives the frizilator (Fig. 6) and produces a very regular 9-min period. Waves start as broad and diffuse ridges. Then, because the Frizilators in a pair of cells that are signaling to each other are brought into synchrony, they sharpen. The precise period of the FruA* driven frizilators and the synchronization of oscillation between colliding cells causes the waves to sharpen. Because of the positive feedback, more signal is produced. Higher levels of C-signal induce higher levels of FruA* (Kim and Kaiser 1991; Kruse et al. 2001; Li et al. 1992).

\section{Aggregation}

As the number of C-signal molecules per cell rises, their signaling elevates the cytoplasmic level of FruA* (Fig. 6) to a threshold. The existence of a threshold that can stop the oscillation is implicit in the negative feedback within the frizilator (Igoshin et al. 2004). Arresting the oscillation leads a developing population of cells to make the transition from traveling waves to aggregates that is evident as the waves fade away and the aggregation centers simultaneously enlarge (Kaiser and Welch 2004). The threshold level of FruA* stops the oscillation by placing all the FrzE in its nonphosphorylated state (Igoshin et al. 2004). There being no more signal to reverse, the cells continue to move in the direction they were moving before their last C-signaling event. This transition in cell reversal behavior is also observed in the tracks of individual cells (Jelsbak and Søgaard-Andersen 2002). The transition leads the cells to form streams; cells trapped in a stream are able to enlarge an aggregate. When a stream of nonreversing cells encounters a dense traffic jam that it cannot penetrate, it is deflected. It turns to glide over or around the traffic jam. Because gliding cells adhere to the surface on which they are moving, they must bend as they pass over or around it. Bending will have distorted the elastic peptidoglycan wall (Wolgemuth 2005) that has some unusual cross-links and unusually short glycan chain length (Bui et al. 2009). Persistence of the bent shape directs the cell into a circular orbit. Cells which are streaming in orbit can continue to C-signal their neighbors, and more positive feedback raises the C-signal level until this population of cells reaches the still higher threshold for the differentiation of spores, which also has been observed experimentally (Gronewold and Kaiser 2001; Kim and Kaiser 1991; Li et al. 1992). In sum, the cell movements of fruiting body morphogenesis can be explained by C-signaling. Details can be found in (Kaiser and Welch 2004).

\section{GENE REGULATORY NETWORK}

Microarray expression profiling of cells at $12 \mathrm{~h}$ into development indicates that nearly 30\% (2134/7388) of the genes are up- or downregulated at least 1.5-fold compared with growing cells (Caberoy et al. 2010). Several key developmental genes like fruA, $\operatorname{csg} A$, and the act operon 
have been noted above in the context of the roles played by their products in fruiting body morphogenesis. How are these and the many other genes that respond to starvation and coordinate fruiting body development regulated?

Although our understanding of the gene regulatory network is far from complete, it is already clear that building a multicellular fruiting body with a defined size and shape requires a network that is highly responsive to environmental, intercellular, and intracellular signals. Analysis of the M. xanthus genome sequence revealed an expansion of multicomponent regulatory pathways because of lineage-specific gene duplications, whereas the number of onecomponent regulators was less than half that expected based on the genome size and comparison with other soil bacteria (Goldman et al. 2006). Multicomponent pathways include two or more proteins with sensory input domains (e.g., sensor domains of protein kinases and receiver domains of response regulators in the familiar two-component systems). These pathways, and connections between them, allow a complexity of signal integration similar to that in multicellular eukaryotes.

Eukaryotic-Like Components of the Network

Some components of the regulatory pathways are similar to proteins first characterized in eukaryotes. M. xanthus encodes 97 serine/ threonine protein kinases (STPKs) and many play a role in fruiting body development (based on the phenotypes of mutants) (Inouye et al. 2008); however, the signal inputs are unknown and in most cases it is also unknown how the protein kinase exerts its effects.

Two types of eukaryotic-like transcription factors are important for the $M$. xanthus response to starvation. A family of 53 enhancerbinding proteins (EBPs) is predicted to activate transcription of particular gene sets by sigma ${ }^{54}$ RNA polymerase (Goldman et al. 2006). Bacterial EBPs typically bind to enhancers located 70-150 bp upstream of the transcription start site and contact sigma ${ }^{54} \mathrm{RNA}$ polymerase via DNA looping to facilitate open complex formation for transcription initiation
(Buck et al. 2000). At least 17 M. xanthus EBPs affect development, although in five of these cases motility on nutrient-rich agar is impaired ( perhaps explaining the defects in fruiting body formation) (Kroos and Inouye 2008). Seven of the development-specific EBPs have aminoterminal CheY-like receiver domains that are presumably phosphorylated by histidine protein kinases (HPKs), forming two-component signal transduction systems, which are common in bacteria, but three EBPs involved in development have amino-terminal fork-head-associated (FHA) domains (Jelsbak et al. 2005). The FHA domain was first recognized in eukaryotic transcription factors and it mediates interactions between proteins by recognizing phosphothreonine (Durocher and Jackson 2002). FHA domain-containing EBPs presumably link STPK signaling pathways to activation of transcription by sigma ${ }^{54}$ RNA polymerase.

The second type of eukaryotic-like transcription factor involved in M. xanthus development is CarD, a protein also important for light-induced carotenogenesis (Elias-Arnanz et al. 2008). Bacterial orthologs of CarD have been found only in myxobacteria, and their DNA-binding domains are similar to those of eukaryotic high-mobility group A proteins or histone $\mathrm{H1}$. These proteins normally modulate chromatin structure but their DNA-binding domains can substitute for that of M. xanthus CarD to permit fruiting body development and carotenogenesis (Garcia-Heras et al. 2009).

\section{Modular Design}

How are eukaryotic-like regulatory proteins and typical bacterial regulators organized into a signal-responsive network to govern gene expression, cell movement, and differentiation during M. xanthus multicellular development? Figure 7 depicts the effects of starvation, including an increase in the intracellular signal (p)ppGpp, which leads to production of the intercellular A- and C-signals. These signals provide input into 3 regulatory modules designated the EBP cascade, Mrp, and FruA in Figure 7. As described above, FruA* is proposed to drive the frizilator that controls cell reversals 


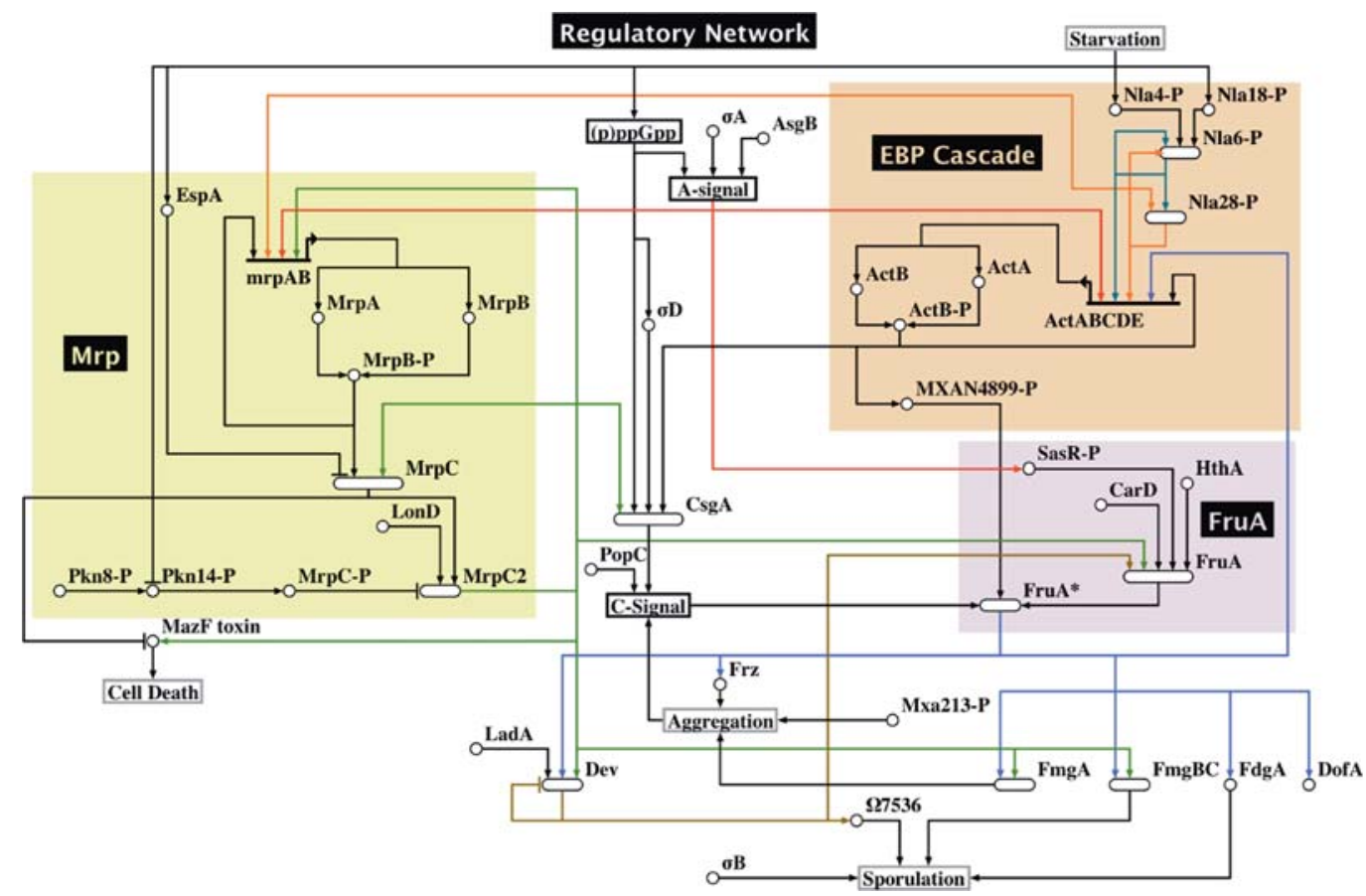

Figure 7. Network diagram of regulation during M. xanthus development. Arrows indicate positive regulation and lines with barred ends indicate negative regulation. Several lines are colored for emphasis. Background colors distinguish three regulatory modules.

(Fig. 6), producing waves and then aggregates. FruA* also is proposed to activate transcription of target genes, often in cooperation with MrpC2 from the Mrp module, and some of the target genes are important for aggregation or sporulation (Fig. 7). The Mrp module also governs programmed cell death. The inputs and outputs of the 3 regulatory modules are described in more detail below.

\section{The EBP Cascade Module}

Six EBPs form a four-step cascade (Caberoy et al. 2010) that responds to starvation and Asignal (Fig. 7). Nla4 and Nla18 have aminoterminal CheY-like and FHA domains that might be phosphorylated by an HPK and an STPK, respectively, in response to starvation. Both Nla4 and Nla18 bind to the promoter region of the gene that codes for Nla6, presumably activating its transcription. The CheY-like domain of Nla6 is presumably phosphorylated by an HPK (in response to an unknown signal) and activates the gene for Nla28 (whose CheYlike domain is also presumably phosphorylated in response to an unknown signal). Nla6 and Nla28 cross-activate, auto-activate, and activate the act $A B C D E$ operon, which codes for the HPK ActA and its presumed substrate EBP, ActB. A-signaling is required for transcription of the act operon (Gronewold and Kaiser 2007) but whether this is because A-signal is sensed at an earlier step in the cascade remains to be tested. ActB auto-activates and it activates the last EBP in the cascade, MXAN4899 (Caberoy et al. 2010), whose FHA domain might be phosphorylated by an STPK (Jelsbak et al. 2005). Output from this module includes (1) a connection to the Mrp module as Nla28 appears to activate $m r p A B$ transcription (A.G. Garza, personal comm.), (2) ActB directly or indirectly increasing expression of $\operatorname{csg} A$ to produce C-signal (Gronewold and Kaiser 2001), and (3) MXAN4899 is proposed to facilitate 
activation of FruA (Jelsbak et al. 2005), providing a connection to the FruA module.

\section{The Mrp Module}

A-signaling might provide a separate input into $m r p A B$ transcription (as depicted in Fig. 7) or it might do so via Nla28 if A-signal is sensed at or before the Nla28 phosphorylation step in the EBP cascade. The mrpAB operon codes for the HPK MrpA and its presumed substrate EBP, MrpB (Sun and Shi 2001). MrpB appears to auto-activate and it appears to activate the gene immediately downstream, $m r p C$. MrpC is a CRP-family transcription factor that is cleaved near its amino terminus to produce MrpC2 (Ueki and Inouye 2003). Starvation not only impacts $m r p A B$ transcription, it affects EspA, an HPK that somehow inhibits mrpC expression posttranscriptionally (Higgs et al. 2008). Also, starvation inhibits accumulation of Pkn14, the second member of an STPK cascade that leads to phophorylation of MrpC, which inhibits LonD-dependent proteolytic conversion of MrpC to MrpC2 (Nariya and Inouye 2005; Nariya and Inouye 2006). The net effect of starvation is to boost MrpC and MrpC2 accumulation. Because MrpC2 binds better than MrpC to certain promoter regions (Nariya and Inouye 2006; Ueki and Inouye 2003), only MrpC2 is depicted in Figure 7 as auto-activating $m r p C$ and activating $\operatorname{mrp} A B$, although MrpC likely contributes to these activities. Likewise, output from the Mrp module in terms of activating target genes fruA (Ueki and Inouye 2003), mazF (Nariya and Inouye 2008), dev (S. Mittal, P. Viswanathan, and L.K., unpublished data), fmgA (Mittal and Kroos 2009a), and fmgBC (Mittal and Kroos 2009b) is depicted solely from MrpC2. On the other hand, only MrpC has been shown to be an antitoxin that binds to the MazF toxin, inhibiting programmed cell death (Nariya and Inouye 2008); whether MrpC2 binds to MazF remains to be tested.

\section{The FruA Module}

If A-signaling provides input into fruA transcription via the SasR EBP (Guo et al. 2000) (as depicted in Fig. 7), this is likely an indirect effect because the fruA promoter is not similar to others recognized by sigma ${ }^{54}$ RNA polymerase. For example, SasR might provide an A-signal-dependent input into the EBP cascade (at the putative sigma ${ }^{54}$-dependent nla6 and/or nla28 promoters) and/or the Mrp module (at the putative sigma ${ }^{54}$-dependent $m r p A B$ promoter), any of which could affect MrpC2 production, which is essential for fruA transcription (Ueki and Inouye 2003). The eukaryotic-like transcription factor CarD (Elias-Arnanz et al. 2008), the putative DNAbinding protein HthA (Nielson et al. 2004), and DevT (Boysen et al. 2002) (in a feedback loop from the dev operon) positively regulate fruA transcription, but whether these are direct inputs is unknown. Two inputs into the FruA module are proposed to stimulate formation of FruA* (Fig. 7). C-signaling (Ellehauge et al. 1998) and MXAN4899 (Jelsbak et al. 2005) have been proposed to cause phosphorylation of FruA, which has a CheY-like receiver domain but it lacks some residues typically required for phosphorylation, its DNA binding was not changed by small molecule phosphodonors (Mittal and Kroos 2009a), and the cognate HPK has not been found. In any case, C-signaling and MXAN4899 do not change the level of FruA, but somehow change its activity, affecting module output, which includes (1) modulation of the Frizilator (Frz in Fig. 7; see also Fig. 6) to bring about aggregation (which enhances C-signaling and therefore FruA ${ }^{*}$ formation in a positive feedback loop), (2) direct or indirect activation of the act operon (Gronewold and Kaiser 2007) (enhancing C-signaling and FruA* formation in a second positive feedback loop), and (3) direct activation of target genes $\operatorname{dev}$ (S. Mittal, P. Viswanathan, and L.K., unpublished data), fmgA (Mittal and Kroos 2009a), fmgBC (Mittal and Kroos 2009b), fdgA (Ueki and Inouye 2005b), and dofA (Ueki and Inouye 2005a), some of which play a role in aggregation or sporulation.

It is worth noting that FruA and MrpC2 bind cooperatively to the promoter regions of $f m g A, f m g B C$, and $d e v$, directly subjecting transcription of these genes to regulation by both the Mrp and FruA modules. Also, transcription 
Myxobacteria, Polarity, and Multicellular Morphogenesis

of the dev operon, which is important for sporulation, requires a third transcription factor, LadA, and cis-regulatory elements spanning $>1 \mathrm{~kb}$ (Viswanathan et al. 2007a; Viswanathan et al. 2007b); complexity resembling regulation of genes in multicellular eukaryotes.

\section{CONCLUDING REMARKS}

Why does $M$. xanthus devote a large amount of energy and protein synthetic capacity to reverse its gliding engines? To enable reversal, both the $A$ and the $S$ engines are always found at both cell poles. However, at each pole only one of the two engines is in working order; the other engine either lacks components that are critical for motor activity (incomplete $\mathrm{S}$ engines), or have additional components that block motor activity (inactive A engines). In addition both the A and the $S$ engines are controlled by MglA $\bullet$ GTP via effector proteins, which regulate the timing of engine assembly and distinguish old and currently active engines from new engines that have yet to function. New engines are made by constitutive growth mechanisms, following instructions from the template that indicate which of the two engines should be active at which pole. Studies of Myxococcus swarming (Wu et al. 2009) show that reversals enable it to build multicellular structures like the rafts and mounds, which are evident in Figure 5, and to build fruiting bodies, Figure 1.

Many biochemical questions remain to be answered concerning engine synthesis and its relation to cell division. Among them, which molecules constitute the proposed template, and how does the template encode direction? Can the inhibition of FrzF protein by FrzE P, postulated for the frizilator, be shown with purified proteins? Which M. xanthus proteins provide the Wza, Wzx, Wzy, and Wba-like functions for capsular polysaccharide synthesis, and how do those proteins feed several polysaccharide chains into a single enlarged Wza-like pore? What is the sugar sequence of the capsular polysaccharide, of the propulsive slime polysaccharide, and are they identical as proposed? How do the Cgl and Agm proteins prevent the nozzles at the leading pole from synthesizing and secreting slime? How are Mgl effector proteins metabolized? Which protein kinase phosphorylates effector RomR and how is that kinase regulated? What is the regulatory target of effector FrzS and what is its action? Is Tgl the target of FrzS or of another effector? How is PilQ disassembled? If by proteolysis, by which protease?

Many unanswered questions concern the control of gene expression and the regulatory networks shown in Figures 6 and 7: How is FruA activated? Does A-signaling directly activate the act operon or does it activate via the EBP cascade module? What are the sensory inputs to the EBPs and what contributions do the nearly one-hundred STPKs make that are found in Myxococcus.

\section{ACKNOWLEDGMENTS}

MR was supported by a fellowship from the Gene Expression in Development and Disease Initiative at Michigan State University. Work in the laboratory of LK was supported by National Science Foundation grant MCB0744343 and by the Michigan Agricultural Experiment Station.

\section{REFERENCES}

Acuna G, Shi W, Trudeau K, Zusman D. 1995. The cheA and cheYdomains of Myxococcus xanthus FrzE function independently in vitro as an autokinase and a phosphate acceptor, respectively. FEBS Letts 358: 31-33.

Astling DP, Lee JY, Zusman DR. 2006. Differential effects of chemoreceptor methylation-domain mutations on swarming and development in the social bacterium Myxococcus xanthus. Mol Microbiol 59: 45-55.

Behmlander RM, Dworkin M. 1994. Biochemical and structural analyses of the extracellular matrix fibrils of Myxococcus xanthus. J Bacteriol. 176: 6295-6303.

Berleman J, Chumley T, Cheung P, Kirby JR. 2006. Rippling is a predatory behavior in Myxococcus xanthus. J Bacteriol 188: $5888-5895$.

Bitter W, Koster M, Latijnhouwers M, de Cock H, Tommassen J. 1998. Formation of oligomeric rings by XcpQ and PilQ, which are involved in protein transport across the outer membrane of Pseudomonas aeruginosa. Mol Microbiol 27: 209-219.

Blackhart BD, Zusman D. 1985a. Frizzy genes of Myxococcus xanthus are involved in control of frequency of reversal of gliding motility. Proc Natl Acad Sci 82: 8767-8770.

Blackhart BD, Zusman DR. 1985b. Cloning and complementation analysis of the frizzy genes of Myxococcus xanthus. Mol Gen Genet 198: 243-254. 
Boysen A, Ellehauge E, Julien B, Søgaard-Andersen L. 2002. The DevT protein stimulates synthesis of FruA, a signal transduction protein required for fruiting body morphogenesis in Myxococcus xanthus. J Bacteriol 184: $1540-1546$.

Buck M, Gallegos MT, Studholme DJ, Guo Y, Gralla JD. 2000. The bacterial enhancer-dependent $\sigma^{54}(\sigma \mathrm{N})$ transcription factor. J Bacteriol 182: 4129-4136.

Bui NK, Gray J, Schwarz H, Schumann P, Blanot D, Vollmer W. 2009. The peptidoglycan sacculus of Myxococcus xanthus has unusual structural features and is degraded during glycerol-induced myxospore development. J Bacteriol 191: 494-505.

Burchard RP. 1970. Gliding motility mutants of Myxococcus xanthus. J Bacteriol 104: 940-947.

Burchard RP. 1974. Growth of surface colonies of the gliding bacterium Myxococcus xanthus. Arch Microbiol 96: 247-254.

Bustamante VH, Martínez-Flores I, Vlamakis HC, Zusman D. 2004. Analsis of the Frz signal transduction system of Myxococcus xanthus shows the importance of the conserved C-terminal region of the cytoplasmic chemoreceptor FrzCD in sensing signals. Mol Microbiol 53: 1501-1513.

Börner U, Deutsch A, Reichenbach H, Bär M. 2002. Rippling patterns in aggregates of myxobacteria arise from cell-cell collisions. Phys Rev Lett 89: 078101.

Caberoy NB, Giglio K, Suen G, Garza AG. 2010. A cascade of enhancer binding proteins regulates gene expression during multicellular development in Myxococcus xanthus. Proc Natl Acad Sci (in press).

Cashel M, Gentry DR, Hernandez VJ, Vinella D. 1996. The stringent response. in Escherichia coli and Salmonella (ed. F. Neidhardt et al.), pp. 1458-1496. ASM Press, Washington, D.C.

Chiang P, Habash M, Burrows LL. 2005. Disparate subcellular localization patterns of Pseudomonas aeruginosa Type IV pilus ATPases involved in twitching motility. J Bacteriol 187: 829-839.

Collins RF, Davidsen L, Derrick JP, Ford RC, Tonjum T. 2001 Analysis of the PilQ secretin from Neisseria meningitidis by transmission electron microscopy reveals a dodecameric quaternary structure. J Bacteriol 183: 3825-3832.

Collins RF, Frye SA, Kitmitto A, Ford RC, Tønjum T, Derrick JP. 2004. Structure of the Neisseria meningitidis outer membrane PilQ secretin complex at $12 \AA$ resolution. J Biol Chem 279: 39750-39756.

Craig L, Volkmann N, Arvai AS, Pique ME, Yeager M, Egelman EH, Tainer JA. 2006. Type IV pilus structure by cryo-electron microscopy and crystallography: Implications for pilus assembly and functions. Mol Cell 23: 651-662.

Curtis PD, Shimkets LJ. 2008. Metabolic pathways relevant to predation, signaling and development. In Myxobacteria, multicellularity and differentiation (ed. D.E. Whitworth), pp. 241-258. ASM Press, Washington, D.C.

D'Andrea LD, Regan L. 2003. TPR proteins: the versatile helix. Trends in Biochem Sci 28: 655-662.

Diodati M, Gill R, Plamann L, Singer M. 2008. Initiation and early developmental events. In Myxobacteria, multicellularity and differentiation (ed. D.E. Whitworth), pp. 43-76. ASM Press, Washington D.C.

Durocher D, Jackson SP. 2002. The FHA domain. FEBS Letts 513: 58-66.

Dworkin M. 1962. Nutritional requirements for vegetative growth of Myxococcus xanthus. J Bacteriol 84: 250-257.

Dworkin M. 1999. Fibrils as extracellular appendages of bacteria: Their role in contact-mediated cell-cell interactions in Myxococcus xanthus. BioEssays 21: 590-595.

Elias-Arnanz M, Fontes M, Panmanabhan S. 2008. Carotinogenesis in Myxococcus xanthus: A complex regulatory network. In Myxobacteria, multicellularity and differentiation (ed. D.E. Whitworth), pp. 211-225. ASM Press, Washington, D.C.

Ellehauge E, Norregaard-Madsen M, Søgaard-Andersen L. 1998. The FruA signal transduction protein provides a checkpoint for the temporal coordination of intercellular signals in Myxococcus xanthus development. Mol Microbiol 30: 807-813.

Evans K, Hobley L, Lambert C, Sockett RE. 2008. Bdellovibrio: Lone hunter cousin of the pack hunting myxobacteria. In Myxobacteria, multicellularity and differentiation (ed. D.E. Whitworth), pp. 351-362. ASM Press, Washington, D.C.

Fontes M, Kaiser D. 1999. Myxococcus cells respond to elastic forces in their substrate. Proc Nat Acad Sci 96: 8052-8057.

Frye SA, Assalkhou R, Collins RF, Ford RC, Petersson C, Derrick JP, Tonjum T. 2006. Topology of the outermembrane secretin PilQ from Neisseria meningitidis. Microbiology 152: 3751-3764.

Garcia-Heras F, Panmanabhan S, Murillo F, Elias-Arnanz M. 2009. Functional equivalence of HMGA- and histone H1-like domains in a bacterial transcription factor. Proc Natl Acad Sci 106: 13546-13551.

Goldman BS, Nierman WC, Kaiser D, Slater SC, Durkin AS, Eisen JA, Ronning CM, Barbazuk WB, Blanchard M, Field C, et al. 2006. Evolution of sensory complexity recorded in a myxobacterial genome. Proc Natl Acad Sci 103: 15200-15205.

Gronewold TMA, Kaiser D. 2001. The act operon controls the level and time of C-signal production for Myxococcus xanthus development. Mol Microbiol 40: 744-756.

Gronewold TMA, Kaiser D. 2007. Mutations of the act promoter in Myxococcus xanthus. J Bacteriol 189: 1836-1844.

Guo D, Wu Y, Kaplan HB. 2000. Identification and characterization of genes required for early Myxococcus xanthus developmental gene expression. J Bacteriol 182: 4564-4571.

Hagen DC, Bretscher AP, Kaiser D. 1978. Synergism between morphogenetic mutants of Myxococcus xanthus. Dev Biol 64: 284-296.

Hansen JK, Forest KT. 2006. Type IV pilin structures: Insights on shared architecture, fiber assembly, receptor binding and type II secretion. J Mol Microbiol Biotechnol 11: $192-207$.

Hartzell P, Kaiser D. 1991a. Function of MglA, a 22-kilodalton protein essential for gliding in Myxococcus xanthus. J Bacteriol 173: 7615-7624. 
Hartzell P, Kaiser D. 1991b. Upstream gene of the $m g l$ operon controls the level of mglA protein in Myxococcus xanthus. J Bacteriol 173: 7625-7635.

Hartzell P, Shi W, Youdarian P. 2008. Gliding motility of Myxococcus xanthus. In Myxobacteria, multicellularity and differentiation (ed. D.E. Whitworth), pp. 103-132. ASM Press, Washington, D.C.

Higgs PI, Jagadeesan S, Mann P, Zusman DR. 2008. EspA, an orphan hybrid histidine protein kinase, regulates the timing of expression of key developmental proteins of $M y x$ ococcus xanthus. J Bacteriol 190: 4416-4426.

Hodgkin J, Kaiser D. 1977. Cell-to-cell stimulation of movement in nonmotile mutants of Myxococcus. Proc Natl Acad Sci 74: 2938-2942.

Hodgkin J, Kaiser D. 1979a. Genetics of Gliding Motility in Myxococcus xanthus (Myxobacterales): Genes Controlling Movement of Single Cells. Mol gen Genet 171: $167-176$.

Hodgkin J, Kaiser D. 1979b. Genetics of Gliding Motility in Myxococcus xanthus (Myxobacterales): Two Gene Systems Control Movement. Mol gen Genet 171: 177-191.

Holbrook SR, Kim S-H. 1989. Molecular model of the G protein a subunit based on the crystal structure of the HRAS protein. Proc Natl Acad Sci 86: 1751-1755.

Igoshin O. 2004. "Modeling pattern formation in myxobacteria". PhD thesis in Physics. University of California, Berkeley.

Igoshin O, Goldbetter A, Kaiser D, Oster G. 2004. A biochemical oscillator explains the developmental progression of myxobacteria. Proc Natl Acad Sci 101: $15760-15765$.

Igoshin O, Mogilner A, Welch R, Kaiser D, Oster G. 2001. Pattern formation and traveling waves in myxobacteria: Theory and modeling. Proc Nat Acad Sci 98: 14913-14918.

Inouye M, Inouye S, Zusman D. 1979. Gene expression during development of Myxococcus xanthus: Pattern of protein synthesis. Devel Biol 68: 579-591.

Inouye S, Nariya H, Munoz-Dorado J. 2008. Protein Ser/ Thr kinases and phosphatases in Myxococcus xanthus. In Myxobacteria, multicellularity and differentiation (ed. D.E. Whitworth), pp. 191-210. ASM Press, Washington, D.C.

Jelsbak L, Kaiser D. 2005. Regulating pilin expression reveals a threshold for type IV pilus assembly in Myxococcus xanthus. J Bacteriol 187: 2105-2112.

Jelsbak L, Givskov M, Kaiser D. 2005. Enhancer-binding proteins with a forkhead-associated domain and the sigma54 regulon in Myxococcus xanthus fruiting body development. Proc Natl Acad Sci 102: 3010-3015.

Jelsbak L, Søgaard-Andersen L. 2002. Pattern formation by a cell-surface associated morphogen in Myxococcus xanthus. Proc Nat Acad Sci 99: 2032-2037.

Kaiser AD. 1979. Social gliding is correlated with the presence of pili in Myxococcus xanthus. Proc Natl Acad Sci 76: 5952-5956.

Kaiser AD, Crosby C. 1983. Cell movement and its coordination in swarms of Myxococcus xanthus. Cell Motility 3: 227-245.

Kaiser D. 2007. Bacterial swarming, a re-examination of cell movement patterns. Current Biology 17: R561-R570.
Kaiser D. 2008a. Reversing Myxococcus xanthus polarity. In Myxobacteria, multicellularity and differentiation (ed. D.E. Whitworth), pp. 93-102. ASM Press, Washington, D.C.

Kaiser D. 2008b. Myxococcus - from single cell polarity to complex multicellular patterns Annu Rev Genetics 42: 109-130.

Kaiser D. 2009. Are there lateral as well as polar engines for A motile gliding in myxobacteria? J Bacteriol 191: 5336-5341.

Kaiser D, Welch R. 2004. Dynamics of fruiting body morphogenesis. J Bacteriol 186: 919-927.

Kaplan HB, Plamann L. 1996. A Myxococcus xanthus cell density-sensing system required for multicellular development. FEMS Microbiol Letters 139: 89-95.

Kearns DB, Shimkets LJ. 2001. Lipid chemotaxis and signal transduction in Myxococcus xanthus. Trends in Microbiol 9: $126-129$.

Kim SK, Kaiser D. 1990a. Cell alignment required in differentiation of Myxococcus xanthus. Science 249: 926-928.

Kim SK, Kaiser D. 1990b. Purification and properties of Myxococcus xanthus C-factor, an intercellular signaling protein. Proc Natl Acad Sci 87: 3635-3639.

Kim SK, Kaiser D. 1991. C-factor has distinct aggregation and sporulation thresholds during Myxococcus development. J Bacteriol 173: 1722-1728.

Kimsey HH, Kaiser D. 1991. Targeted disruption of the Myxococcus xanthus orotidine 5'-monophosphate decarboxylase gene: Effects on growth and fruiting-body development. J Bacteriol 173: 6790-6797.

Koonin E, Aravind L. 2001. Dynein light chains of the roadblock/LC7 group belong to an ancient protein superfamily implicated in NTPase regulation. Current Biology 10: R774-R776.

Kroos L, Hartzell P, Stephens K, Kaiser D. 1988. A link between cell movement and gene expression argues that motility is required for cell-cell signalling during fruiting body development. Genes and Devel 2: 1677-1685.

Kroos L, Inouye S. 2008. Transcriptional regulatory mechanisms during Myxococcus xanthus development. In Myxobacteria, multicellularity and differentiation (ed. D.E. Whitworth), pp. 149-168. ASM Press, Washington, D.C.

Kruse T, Lobendanz S, Bertheleson NMS, Søgaard-Andersen L. 2001. C-signal: A cell surface-associated morphogen that induces and coordinates multicellular fruiting body morphogenesis and sporulation in Myxococcus xanthus. Mol Microbiol 40: 156-168.

Kuhlwein H, Reichenbach H. 1968. Swarming and morphogenesis in Myxobacteria Film C893/1965 Institut fur den Wissensch Film, Gottingen, Germany.

Kuspa A, Kroos L, Kaiser D. 1986. Intercellular signaling is required for developmental gene expression in Myxococcus xanthus. Dev Biol 117: 267-276.

Kuspa A, Plamann L, Kaiser D. 1992a. Identification of heatstable A-factor from Myxococcus xanthus. J Bacteriol 174: 7360-7369.

Kuspa A, Plamann L, Kaiser D. 1992b. A-signalling and the cell density requirement for Myxococcus xanthus development. J Bacteriol 174: 7360-7369. 
Leonardy S, Bulyha I, Søgaard-Andersen L. 2008. Reversing cells and oscillating motility proteins. Mol Biosyst 4: 1009-1014.

Leonardy S, Freymark G, Hebener S, Ellehauge E, Søgaard-Andersen L. 2007. Coupling of protein localization and cell movement by a dynamically localized response regulator in Myxococcus xanthus. EMBO J. 26: 4433-4444.

Li S, Lee BU, Shimkets L. 1992. csgA expression entrains Myxococcus xanthus development. Genes and Devel 6: 401-410.

Li Y, Sun H, Ma X, Lu A, Lux R, Zusman D, Shi W. 2003. Extracellular polysaccharides mediate pilus retraction during social motility of Myxococcus xanthus. Proc Nat Acad Sci 100: 5443-5448.

Lobedanz S, Søgaard-Andersen L. 2003. Identification of the C-signal, a contact-dependent morphogen coordinating multiple developmental responses in Myxococcus xanthus. Genes and Devel 17: 2151-2161.

Lu A, Cho K, Black WP, Duan X-y, Lux R, Yang Z, Kaplan HB, Zusman D, Shi W. 2005. Exopolysaccharide biosynthesis genes required for social motility in Myxococcus xanthus. Mol Microbiol 55: 206-220.

Maier B, Potter L, So M, Seifert HS, Sheetz MP. 2002. Single pilus motor forces exceed 100 pN. Proc Natl Acad Sci 99: 16012-16017.

Manoil C, Kaiser D. 1980a. Accumulation of guanosine tetraphosphate and guanosine pentaphosphate in Myxococcus xanthus during starvation and myxospore formation. J Bacteriol 141: 297-304.

Manoil C, Kaiser D. 1980b. Guanosine pentaphosphate and guanosine tetraphosphate accumulation and induction of Myxococcus xanthus fruiting body development. J Bacteriol 141: 305-315.

Mattick JS. 2002. Type IV pili and twitching motility. Annu Rev Microbiol 56: 289-314.

Mauriello E, Nan B, Zusman D. 2009b. AglZ regulates adventurous [A-] motility in Myxococcus xanthus through its interaction with the cytoplasmic receptor, FrzCD. Molecular Microbiol 72: 964-977.

Mauriello E, Astling DP, Sliusarenko O, Zusman D. 2009a. Localization of a bacterial cytoplasmic receptor is dynamic and changes with cell-cell contacts. Proc Natl Acad Sci 106: 4852-5857.

McBride M, Kohler T, Zusman D. 1992. Methylation of FrzCD, a methyl-accepting taxis protein of Myxococcus xanthus is correlated with factors affecting cell behavior. J Bacteriol 174: 4246-4257.

McCleary WR, Zusman DR. 1990a. FrzE of Myxococcus xanthus is homologous to both CheA and CheYof Salmonella typhimurium. Proc Natl Acad Sci 87: 5898-5902.

McCleary WR, Zusman DR. 1990b. Purification and characterization of the Myxococcus xanthus FrzE protein shows that it has autophosphorylation activity. J Bacteriol 172: 6661-6668.

McCleary WR, McBride MJ, Zusman DR. 1990. Developmental sensory transduction in Myxococcus xanthus involves methylation and demethylation of frzCD. J Bacteriol 172: 4877-4887.

Merz AJ, So M, Sheetz MP. 2000. Pilus retraction powers bacterial twitching motility. Nature 407: 98-102.
Mignot T, Merlie JP, Zusman D. 2005. Regulated pole-to-pole oscillations of a bacterial gliding motility protein. Science 310: 855-857.

Mignot T, Shaevitz J, Hartzell P, Zusman D. 2007. Evidence that focal adhesions power bacterial gliding motility. Science 315: 853-856.

Mittal S, Kroos L. 2009a. A combination of unusual transcription factors binds cooperatively to control Myxococcus xanthus developmental gene expression. Proc Natl Acad Sci 106: 1965-1970.

Mittal S, Kroos L. 2009b. Combinatorial regulation by a novel arrangement of FruA and $\mathrm{MrpC} 2$ transcription factors during Myxococcus xanthus development. J Bacteriol 191: $2753-2763$.

Nariya H, Inouye S. 2005. Identification of a protein Ser/ Thr kinase cascade that regulates essential transcriptional activators in Myxococcus xanthus development. Mol Microbiol 58: 367-379.

Nariya H, Inouye S. 2006. A protein Ser/Thr kinase cascade negatively regulates the DNA-binding activity of $\mathrm{MrpC}$, a smaller form of which may be necessary for Myxococcus xanthus development. Mol Microbiol 60: 1205-1217.

Nariya H, Inouye M. 2008. MazF, an mRNA interferase, mediates programmed cell death during multicellular Myxococcus development. Cell 132: 55-66.

Nesper J, Hill CMD, Paiment A, Harauz G, Beis K, Naismith JH, Whitfield C. 2003. Translocation of group 1 capsular polysaccharide in Escherichia coli serotype K30. J Biol Chem 278: 49763-49772.

Nielson M, Rasmussen A, Ellehauge E, Treuner-Lange A, Søgaard-Andersen L. 2004. HthA, a putative DNAbinding protein, and $\mathrm{HthB}$ are important for fruiting body morphogenesis. Microbiology 150: 2171-2183.

Nudleman E, Kaiser D. 2004. Pulling together with type IV pili. J Molec Microbiol Biotechnol 7: 52-62.

Nudleman E, Wall D, Kaiser D. 2005. Cell-to-cell transfer of bacterial outer-membrane lipoproteins. Science 309: $125-127$.

Nudleman E, Wall D, Kaiser D. 2006. Polar assembly of the type IV pilus secretin in Myxococcus xanthus. Mol Microbiol 60: 1205-1217.

Nunn D, Bergman S, Lory S. 1990. Products of three accessory genes, pilB, pilC, and pilD, are required for biogenesis of Pseudomonas aeruginosa pili. J Bacteriol 172: 2911-2919.

Pai E, Kabsch W, Krengel U, Holmes KC, John J, Wittinghofer A. 1989. Structure of the guanine-nucleotidebinding domain of the Ha-ras oncogene product p21 in the triphosphate conformation. Nature 341: 209-214.

Paiment A, Hocking J, Whitfield C. 2002. Impact of phosphorylation of specific residues in the tyrosine autokinase, Wzc, on its activity in assembly of group 1 capsules in Escherichia coli J Bacteriol 184: 6437-6447.

Pearce M, Mintseris J, Ferreyra J, Gygi S, Darwin KH. 2008. Ubiquitin-like protein involved in the proteasome pathway of Mycobacterium tuberculosis Science 322: 1104-1107.

Pelicic V. 2008. Type IV pili: e pluribus unum? Mol Microbiol 68: $827-837$.

Purcell EM. 1977. Life at low Reynolds number. Am J Phys 45: 3-11. 
Pérez J, Castañeda-García A, Jenke-Kodama H, Müller R, Muñoz-Dorado J. 2008. Eukaryotic-like protein kinases in the prokaryotes and the myxobacterial kinome. Proc Natl Acad Sci 105: 15950-15955.

Reichenbach H. 1966. Myxococcus spp (Myxobacteriales) Schwarmentwicklung und Bildung von Protocysten Film E778 Inst fur den Wissensch. Film, Gottingen, Germany.

Reichenbach H. 1968. Archangium violaceum (Myxobacteriales) Schwarmentwicklung und bildung von protocysten Film E 777/1965 Institut fur den Wissensch. Film, Gottingen, Germany.

Reichenbach H. 1974. Chondromyces apiculatus (Myxobacteriales) Schwarmentwicklung und morphogenese Film E 779/1965 Institut fur den Wissensch. Film, Gottingen, Germany.

Reichenbach H. 1984. Myxobacteria: a most peculiar group of social prokaryotes. In Myxobacteria (ed E. Rosenberg), pp. 1-50. Springer-Verlag, New York.

Reichenbach H. 1993. Biology of the Myxobacteria: Ecology and Taxonomy. In Myxobacteria II 404 pps (ed. M. Dworkin and D. Rosenberg), pp. 13-62. ASM Press, Washington D.C.

Reichenbach H, Dworkin M. 1969. Studies on Stigmatella aurantiaca. J Gen Microbiol 58: 3-14.

Rodriguez AM, Spormann AM. 1999. Genetic and molecular analysis of $c g l B$, a gene essential for single-cell gliding in Myxococcus xanthus. J Bacteriol 181: 4381-4390.

Rodriguez-Soto JP, Kaiser D. 1997a. Identification and localization of the $t g l$ protein, which is required for Myxococcus xanthus social motility. J Bacteriol 179: 4372-4381.

Rodriguez-Soto JP, Kaiser D. 1997b. The tgl gene: Social motility and stimulation in Myxococcus xanthus. J Bacteriol 179: 4372-4381.

Rolbetski A, Ammon M, Jakovljevic V, Konovalova A, Søgaard-Andersen L. 2008. Regulated secretion of a protease activity activates intercellular signaling during fruiting body formation in M. xanthus. Developmental Cell 15: $627-634$.

Sager B, Kaiser D. 1994. Intercellular C-signaling and the traveling waves of Myxococcus. Genes Devel 8: 2793-2804.

Satyshur K, Worzalla G, Meyer L, Heiniger E, Aukema K, Misic A, Forest KT. 2007. Crystal structures of the pilus retraction motor PilT suggests large domain movements and subunit cooperation drive motility. Structure 15: 363-376.

Schneiker S, Perlova O, Alici A, Altmeyer MO, Bartels D, Bekel T, Beyer S, Blöcker H, Bode E, Bode HB, et al. 2007. Complete sequence of the largest known bacterial genome from the myxobacterium Sorangium cellulosum. Nature Biotechnology 25: 1281-1289.

Semmler ABT, Whitchurch CB, Mattick JS. 1999. A re-examination of twitching motility in Pseudomonas aeruginosa. Microbiology 145: 2863-2873.

Shimkets LJ, Gill RE, Kaiser D. 1983. Developmental cell interactions in Myxococcus xanthus and the spoC locus. Proc Natl Acad Sci 80: 1406-1410.

Simunovic V, Gherardini FC, Shimkets LJ. 2003. Membrane localization of motility, signaling, and polyketide synthase proteins in Myxococcus xanthus. J Bacteriol 185: 5066-5075.
Singer M, Kaiser D. 1995. Ectopic production of guanosine pent-and tetraphosphate can initiate early developmental gene expression in Myxococcus xanthus. Genes Dev 9: $1633-1644$.

Sozinova O, Jang Y, Kaiser D, Alber M. 2006. A ThreeDimensional Model of Myxobacterial Fruiting Body Formation. Proc Natl Acad Sci 103: 17255-17259.

Sozinova O, Jang Y, Kaiser D, Alber MS. 2005. Threedimensional model of myxobacterial aggregation by contact-mediated interaction. Proc Natl Acad Sci 102: 11308-11312.

Spormann AM, Kaiser D. 1999. Gliding mutants of Myxococcus xanthus with high reversal frequencies and small displacements. J Bacteriol 181: 2593-2601.

Sproer C, Reichenbach H, Stackebrandt E. 1999. Correlation between morphological and phylogenetic classification of myxobacteria. Int J Syst Bacteriol 49: 1255-1262.

Stanier RY. 1942. Elasticotaxis in Myxobacteria. J Bacteriol 44: 405-412.

Stevens A, Søgaard-Andersen L. 2005. Making waves: Pattern formation by a cell-surface-associated signal. Trends in Microbiology 13: 249-252.

Stock JB, Surette MG, Levit M, Park P. 1995. Two component signal transduction systems: Structure-function relationships and mechanism of catalysis. In Two component signal transduction (ed. J.A. Hoch and T.J. Silhavy), pp. 25-51. ASM Press, Washington, D.C.

Strom MS, Nunn DN, Lory S. 1993. A single bifunctional enzyme, PilD, catalyzes cleavage and N-methylation of proteins belonging to the type IV pilin family. Proc Natl Acad Sci 90: 2404-2408.

Sun H, Shi W. 2001. Genetic studies of $m r p$, a locus essential for cellular aggregation and sporulation of Myxococcus xanthus. J Bacteriol 183: 4786-4795.

Søgaard-Andersen L. 2008. Contact-dependent signaling in Myxococcus xanthus: The function of the C-signal in fruiting body morphogenesis. (ed. D.E. Whitworth), pp. 77-91. ASM Press, Washington, D.C.

Thaxter R. 1892. On the Myxobacteriaceae, a new order of Schizomycetes. Bot Gaz 17: 389-406.

Tzeng L-F, Singer M. 2005. DNA replication during sporulation in Myxococcus xanthus fruiting bodies. Proc Natl Acad Sci 102: 14428-14433.

Tzeng L-F, Ellis TN, Singer M. 2006. DNA replication during aggregation phase is essential for Myxococcus xanthus development. J Bacteriol 188: 2774-2779.

Ueki T, Inouye S. 2003. Identification of an activator protein required for the induction of $f r u A$, a gene essential for fruiting body development in Myxococcus xanthus. Proc Natl Acad Sci 100: 8782-8787.

Ueki T, Inouye S. 2005a. Activation of a developmentspecific gene, dofA, by FruA, an essential transcription factor for development of Myxococcus xanthus. J Bacteriol 187: $8504-8506$

Ueki T, Inouye S. 2005b. Identification of a gene involved in polysaccharide export as a transcription target of FruA, an essential factor for Myxococcus xanthus development. J Biol Chem 280: 32279-32284.

Viswanathan P, Murphy K, Julien B, Garza AG, Kroos L. 2007a. Regulation of $d e v$, an operon that includes genes essential for Myxococcus xanthus development and 
D. Kaiser, M. Robinson, and L. Kroos

CRISPR-associated genes and repeats. J Bacteriol 189: 3738-3750.

Viswanathan P, Ueki T, Inouye S, Kroos L. 2007b. Combinatorial regulation of genes essential for Myxococcus xanthus development involves an upstream response regulator and a downstream LysR-type regulator. Proc Natl Acad Sci 104: 7969-7974.

Ward MJ, Lew H, Zusman DR. 2000. Social motility in Myxococcus xanthus requires FrzS, a novel protein with an extensive coiled-coil domain. Mol Microbiol 37: 1357-1371.

Welch R, Kaiser D. 2001. Cell behavior in traveling wave patterns of myxobacteria. Proc Natl Acad Sci 98: 1490714912.

White DJ, Hartzell PL. 2000. AglU, a protein required for gliding motility and spore maturation of Myxococcus xanthus, is related to WD-repeat proteins. Mol Microbiol 36: $662-678$.

Whitfield C, Roberts IS. 1999. Structure, assembly and regulation of expression of capsules in Escherichia coli. Mol Microbiol 31: 1357-1371.

Wolgemuth C. 2005. Force and flexibility of flailing myxobacteria. Biophys J 89: 945-950.

Wolgemuth C, Hoiczyk E, Kaiser D, Oster G. 2002. How myxobacteria glide. Current Biology 12: 369-377.
Wu SS, Kaiser D. 1997. Regulation of expression of the pilA gene in Myxococcus xanthus. J Bacteriol 179: 7748-7758.

Wu SS, Wu J, Kaiser D. 1997. The Myxococcus xanthus pilT locus is required for social gliding motility although pili are still produced. Molec Microbiol 23: 109-121.

Wu Y, Kaiser D, Jiang Y, Alber M. 2007. Social interactions in myxobacterial swarming. PLoS Comp Biol 31: e253. doi: 210.1371/journal.pcbi.0030253.

Wu Y, Kaiser D, Jiang Y, Alber M. 2009. Periodic reversal of direction allows Myxobacteria to swarm. Proc Natl Acad Sci 106: $1222-1227$.

Wugeditsch T, Paiment A, Hocking J, Drummelsmith J, Forrester C, Whitfield C. 2001. Phosphorylation of Wzc, a tyrosine autokinaase, is essential for assembly of group 1 capsular polysaccharides in Escherichia coli. J Biol Chem 276: 2361-2371.

Yang R, Bartle S, Otto R, Stassinopoulos A, Rogers M, Plamann L, Hartzell P. 2004. AglZ is a filament-forming coiled-coil protein required for adventurous gliding motility of Myxococcus xanthus. J Bacteriol 186: 6168-6178.

Youderian P, Burke N, White DJ, Hartzell PL. 2003. Identification of genes required for adventurous gliding motility in Myxococcus xanthus with the transposable element mariner. Mol Microbiol 49: 555-570.

Yu R, Kaiser D. 2007. Gliding motility and polarized slime secretion. Molecular Microbiol 63: 454-467. 


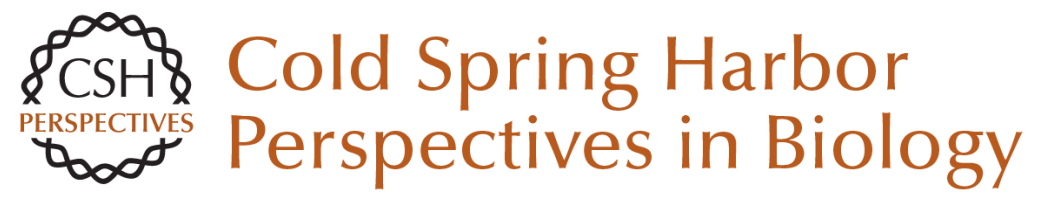

\section{Myxobacteria, Polarity, and Multicellular Morphogenesis}

Dale Kaiser, Mark Robinson and Lee Kroos

Cold Spring Harb Perspect Biol 2010; doi: 10.1101/cshperspect.a000380 originally published online July 7, 2010

\section{Subject Collection Cell Biology of Bacteria}

\section{Electron Cryotomography}

Elitza I. Tocheva, Zhuo Li and Grant J. Jensen

Protein Subcellular Localization in Bacteria David Z. Rudner and Richard Losick

Poles Apart: Prokaryotic Polar Organelles and Their Spatial Regulation

Clare L. Kirkpatrick and Patrick H. Viollier

Myxobacteria, Polarity, and Multicellular

Morphogenesis

Dale Kaiser, Mark Robinson and Lee Kroos

Membrane-associated DNA Transport Machines Briana Burton and David Dubnau

The Bacterial Cell Envelope

Thomas J. Silhavy, Daniel Kahne and Suzanne Walker

Cell Biology of Prokaryotic Organelles Dorothee Murat, Meghan Byrne and Arash Komeili

Bacterial Chromosome Organization and

\section{Segregation}

Esteban Toro and Lucy Shapiro

\author{
Cyanobacterial Heterocysts \\ Krithika Kumar, Rodrigo A. Mella-Herrera and \\ James W. Golden
}

Synchronization of Chromosome Dynamics and

Cell Division in Bacteria Martin Thanbichler
Automated Quantitative Live Cell Fluorescence Microscopy Michael Fero and Kit Pogliano

The Structure and Function of Bacterial Actin

Homologs Joshua W. Shaevitz and Zemer Gitai

\section{Biofilms} Daniel López, Hera Vlamakis and Roberto Kolter

Bacterial Nanomachines: The Flagellum and Type

III Injectisome Marc Erhardt, Keiichi Namba and Kelly T. Hughes

Single-Molecule and Superresolution Imaging in Live Bacteria Cells Julie S. Biteen and W.E. Moerner

For additional articles in this collection, see http://cshperspectives.cshlp.org/cgi/collection/

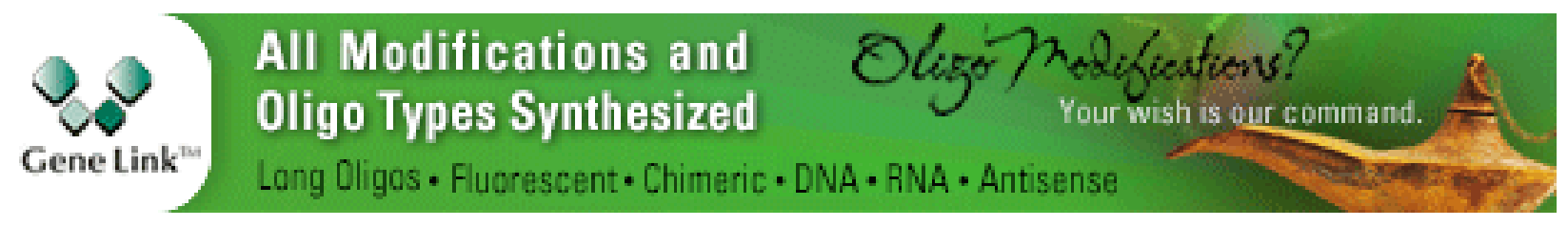

Copyright @ 2010 Cold Spring Harbor Laboratory Press; all rights reserved 